\title{
¡HAGÁMOSLO POR DIOS Y POR LA PATRIA! LA ORGANIZACIÓN DE LAS MUJERES CATÓLICAS EN LAS ELECCIONES DE NOVIEMBRE DE 1933
}

\section{LET'S DO IT FOR GOD AND HOMELAND! CATHOLIC WOMEN'S ORGANIZATION IN THE ELECTIONS OF NOVEMBER 1933}

\author{
Rosa Ana Gutiérrez Lloret \\ Universidad de Alicante
}

SUMARIO: I. LA MOVILIZACIÓN CATÓLICA FEMENINA EN LOS AÑOS VEINTE: UN PRECEDENTE DE LA ACTUACIÓN DE LAS MUJERES CATÓLICAS EN 1933 II. EL VOTO DE LAS MUJERES, UN ARMA POLÍTICA EN LA OFENSIVA CATÓLICA CONTRA LA REPUBLICA - III. LA CONSTITUCIÓN DE LAS AGRUPACIONES POLÍTICAS FEMENINAS DE LA DERECHA CATÓLICA - IV. ORGANIZACIÓN Y ACTUACION DE LAS SECCIONES FEMENINAS - 1. Modelo organizativo - 2. Formación política y control del censo electoral - 3. Propaganda y prensa $-\mathrm{V}$. A MODO DE CONCLUSIÓN

Resumen: La nueva Constitución de 1931 concedió el derecho a voto a las mujeres y las formaciones derechistas lo concibieron como un arma politica en la contraofensiva católica contra la República. Estos partidos promovieron la creación de agrupaciones femeninas con el objetivo de movilizarlas electoralmente a favor de los partidos de la derecha católica. Este estudio analiza el proceso de configuración de estas agrupaciones femeninas derechistas y su trabajo en la organización electoral y en la propaganda previa a las elecciones de 1933.

Abstract: The new Constitution of 1931 granted women the right to vote. Rightwing parties saw it as a political weapon in the Catholic counter-offensive against Spanish Republic. These parties promoted the creation of women's groups as a means of mobilising electoral support. This study analyses the process of group formation of right-wing women's associations and their role in electoral politics and propaganda before the 1933 elections.

Palabras clave: Segunda República española, derecha católica, mujeres, partidos políticos, agrupaciones femeninas, movilización política

Keywods: Second Spanish Republic, catholic right-wing, women, political parties, women's groups, political mobilization

"Hoy ya no basta a las mujeres orad como Maria, es necesario trabajar como Marta, hasta alcanzar la victoria por Cristo y por España" Acción. Defensor de los intereses de la Mujer, Gijón, 5-3-1932 
Tras las elecciones Constituyentes del 28 de junio de 1931, el artículo 34 del proyecto constitucional de la Segunda República -que sería el artículo 36 en la redacción definitiva de la Constitución- señalaba que "los ciudadanos de uno y otro sexo, mayores de veintiún años tendrán los mismos derechos electorales, conforme a lo que dictaminen las leyes". Con ello se ponía fin a la exclusión de las mujeres en el ejercicio de la ciudadanía plena y de los derechos políticos impuesta por la legislación constitucional del liberalismo decimonónico ${ }^{1}$. El día 30 de septiembre comenzó a discutirse este artículo que suscitó la oposición de diversos diputados, que eran contrarios a este derecho o partidarios de aplazarlo en el tiempo, utilizando diversas argumentaciones de matriz biologicista, esencialista, o de la conveniencia política para la República ${ }^{2}$. No obstante, la atención del debate se centró en el duelo dialéctico entre Clara Campoamor y Victoria Kent, ambas diputadas por la circunscripción de Madrid. Para esta última, la discusión se centraba no en la capacidad de la mujer para ejercer el derecho al sufragio, pues indudablemente la tenía, sino en la oportunidad política para concederlo en ese momento, defendiendo un aplazamiento del sufragio femenino por la incultura política de las mujeres, su falta de preparación y de independencia de conciencia y la notable influencia de la Iglesia sobre ella que, a su juicio, inclinarian el voto a las fuerzas de la derecha conservadora y católica, argumentos que compartian otros diputados republicanos. La tradicional imagen de la mujer esencialmente católica y conservadora actuaba como un catalizador de las posiciones contra del sufragio femenino, pero también a favor del mismo, porque esa misma percepción tenían las fuerzas conservadoras y católicas que con un sentido utilitarista pensaban que inclinaría hacia ellas la balanza electoral en futuras elecciones. Aun siendo un estereotipo, en aquellos republicanos contrarios a la concesión inmediata del voto a las mujeres subyacía el temor a una movilización intensa por parte de las mujeres católicas y de las organizaciones y asociaciones que controlaban; una percepción que parecía confirmar la constante defensa del voto femenino que, por parte de algunos propagandistas, asociaciones y periódicos de filiación católica, se venía realizando desde noviembre de $1919 .^{3}$

1 Mary Nash, "Género y Ciudadania”, en Ayer, 20, 1995, pp. 241-258; Ana Aguado, "Ciudadania, mujeres y democracia", Historia constitucional, n ${ }^{\circ}$ 6, pp. 11-27, 2005, http://www.historiaconstitucional.com -2017) (consultado el 17-5-2017).

2 Una sintesis en Nerea Aresti, "Los argumentos de la exclusión. Mujeres y liberalismo en la España contemporánea", Historia Constitucional, $\mathrm{n}^{\circ}$ 13, 2012, pp. 407-431, esp. pp. 424-431, http://www.historiaconstitucional.com (consultado el 25-4-2017). Sobre el debate parlamentario existe una importante bibliografia de referencia, en la que se puede citar los trabajos pioneros de Rosa M ${ }^{\mathrm{a}}$ Capel Martínez, El sufragio femenino en la Segunda República Española, Universidad de Granada, Granada, 1975 y Concha Fagoaga, La voz y el voto de las mujeres. El sufragismo en España: 1877-1931, Icaria, Barcelona, 1985. Véase también M Dolores Ramos, "Luces y sombras en torno a una polémica: La concesión del voto femenino en España (1931-1933", Baetica, n 11 , 1988, pp. 563-573, y Ana Aguado, "Entre lo público y lo privado: sufragio y divorcio en la Segunda República”, Ayer, 60, 2005, pp. 105-234.

3 Rosa Ana Gutiérrez Lloret, "Las católicas y la politica: del apostolado a la propaganda y la movilización (1900-1924)", en $\mathrm{M}^{\mathrm{a}}$ Concepción Marcos del Olmo; Rafael Serrano García, Mujer y política en la España Contemporánea (1868-1936), Valladolid, Universidad de Valladolid, 2012, pp. 159-181, esp. 172 y ss. 


\section{LA MOVILIZACión CATÓlica FEMENINA EN LOS AÑOS VEINTE: UN PRECEDENTE DE LA ACTUACIÓN DE LAS MUJERES CATÓLICAS EN 1933}

En el contexto del proyecto de recristianización que la Iglesia impulsó en los primeros decenios del siglo XX en respuesta a la que consideraban la amenaza secularizadora del Estado y de la sociedad, las mujeres alcanzaron un progresivo protagonismo a través del movimiento católico ${ }^{4}$. Esta mayor proyección pública les había permitido articular con una cierta autonomia sus propias redes de sociabilidad, que incorporaban las tradicionales funciones devocionales, piadosas y benefactoras a un proyecto más moderno de apostolado social ${ }^{5}$. En la cultura política conformada en torno al movimiento católico las mujeres desempeñaron un papel fundamental en la propaganda, movilización, asociacionismo y proselitismo que les permitió ir configurando una nueva identidad que redefinía el modelo de las dos esferas y la proyección exterior de la maternidad social bajo otra modalidad de feminismo -que denominaron feminismo católico6- e ir asumiendo ciertas propuestas de emancipación que, aunque en principio no eran sufragistas, tuvieron una dimensión política creciente en un contexto cada vez más abierto a la politización y a la nueva política de masas.

Exponentes de esa creciente movilización de las mujeres católicas serán las asociaciones de Damas de la Buena Prensa y los sindicatos católicos femeninos, que se convertirán en auténticas escuelas de ciudadanía para sus asociadas ${ }^{7}$. A

\footnotetext{
${ }^{4}$ Sobre el movimiento católico español, la referencia clásica de Feliciano Montero, El Movimiento Católico en España, Eudema, Madrid, 1993. Del mismo autor, una versión ampliada y revisada en El Movimiento Católico en España, 1889-1936, Universidad de Alcalá, Madrid, 2017.

5 Al respecto, diversos trabajos de Inmaculada Blasco Herranz, Paradojas de la ortodoxia: politica de masas y militancia católica femenina en España (1919-1939), Universidad de Zaragoza, Zaragoza, 2003; "Ciudadanía y militancia católica femenina en la España de los años veinte", Ayer, 57, 2005, pp. 223-246 y “¿Católicas a la calle? Género y religión en el movimiento católico (1890-1913)", en Aurora Bosch, Ismael SAZ CAMPOS (coord.), Izquierdas y derechas ante el espejo: culturas politicas en conflicto, Ed. Tirant, Valencia, 2016, pp. 253-274.

${ }^{6} \mathrm{El}$ feminismo católico tomaba como referencia las obras de Concepción Arenal, algunos escritos de los religiosos Julio Alarcón y Graciano Martínez, o de las propias propagandistas, como Concepción Gimeno de Flaquer, Dolors Monserdá, Teresa Luzzatti, María de Echarri y Juana Salas. Su expresión más acabada sería la creación de Acción Católica de la Mujer en 1919. Sobre el feminismo católico, Inmaculada Blasco Herranz, "El feminismo católico", en Historia de las mujeres en España y América Latina, vol. IV: Del siglo XX a los umbrales del XXI, Cátedra, Madrid, 2008, $2^{\text {a }}$ ed., pp.55-75; Nerea Aresti: "Cuestión de dignidad, género, feminismo y culturas políticas”, en Carlos Forcadell, Manuel Suárez Cortina (Coords.), Historia de las culturas políticas en España y América Latina. Vol. III: La Restauración y la República, 1874-1936, Marcial Pons, Madrid, 2015, pp. 85-110, esp. pp. 89-94.

7 La creación de los sindicatos femeninos católicos, como el Patronato de las Obreras de la Aguja en Barcelona, la Federación Sindical de Obreras de Barcelona, el Sindicato Católico Femenino de la Inmaculada de Madrid, y otros similares existentes en diversas ciudades españolas, constituye uno de los de los frentes de actuación del feminismo católico para contrarrestar la influencia socialista entre las obreras. Véase María de Echarri, "Acción Social de la Mujer", en Semana Social de España: segundo curso, Valencia, 12 al 19 diciembre de 1907, Zaragoza, 1908, pp. 415-448. Sobre el asociacionismo católico catalán, véase Amelia García Checa, Ideología y práctica de la acción social católica femenina. Cataluña, 1900-1930, Universidad de Málaga, Málaga, 2007. Sobre el Sindicato de la Inmaculada como reacción defensiva al avance del sindicalismo socialista y republicano, véase Marta del Moral Vargas, "De rodillas para rezar. ¡De pie para combatir!: El enfrentamiento entre católicas y socialistas por asociar a las trabajadoras de Madrid (1906-1927)", en Julio de la Cueva Merino, Feliciano Montero García (Eds.): Izquierda obrera y religión en España (1900-1939), Universidad de Alcalá de Henares, 2012, pp. 179-198.
} 
medida que la acción femenina católica y su asociacionismo se ampliaban, la actuación pública de las católicas fue cada vez más visible. Sin olvidar los tradicionales actos piadosos en defensa de la moralidad católica y de la religión, las militantes del feminismo católico fueron capaces de poner en práctica campañas movilizadoras de alcance politico ${ }^{8}$, como la desarrollada contra las escuelas laicas en el primer semestre de 1910, que incluyó multitudinarias conferencias y mitines de señoras, que se atrevian a descender a lo que ellas mismas calificaban de "sucia arena del circo politico"9.

Desde finales de 1919, con el proyecto de ley electoral presentado por Burgos y Mazo, que contemplaba la posibilidad del voto femenino, se suscitó un intenso debate en torno a tal posibilidad y en el ámbito de la prensa y asociaciones católicas -también femeninas - comienzan a vislumbrarse posturas proclives a la participación política plena de las mujeres. Durante la dictadura de Primo de Rivera, el Estatuto Municipal de marzo de 1924, concedió el voto a las mujeres cabezas de familia, solteras y viudas y la posibilidad de ser elegibles a las mayores de 25 años, y fue aceptado por las militantes católicas no como un derecho, sino como un deber y un instrumento para desarrollar mejor la acción social femenina bajo la cobertura institucional10. En virtud del Estatuto municipal, algunas mujeres accedieron a la representación política municipal y nacional en la Asamblea Nacional, muchas de ellas estrechamente ligadas a las asociaciones católicas. La senda de la política se había abierto y la defensa del sufragio femenino era ya para muchas de ellas un objetivo irrenunciable desde 1928. Con la República la ansiada ciudadanía política femenina había llegado y con ella, la organización política de las mujeres católicas y su movilización "por Dios y por la Patria", que constituye uno de los aspectos más singulares de las elecciones generales celebradas en $1933^{11}$.

8 Este tipo de acciones se harán más frecuentes a partir de 1917. Sirvan como ejemplos, la exposición al Ministro de la Gobernación solicitando la jornada de 9 horas como máximo para las obreras y el estricto cumplimiento de la ley de descanso dominical presentada por el Sindicato Madrileño de la Inmaculada en diciembre de 1917 (Revista Católica de Cuestiones Sociales, $\mathrm{n}^{\circ} 277$, enero de 1918, pp.37-40), el mitin de modistas de Barcelona y el I Congreso de Trabajo, patrocinados por la Liga de Señoras Católicas y el Sindicato de la Aguja en junio y noviembre de 1917 (Acción Femenina Católica, n 68, junio de 1917 y n n 73, noviembre de 1917).

9 Por ejemplo, los mitines de Villarreal, en el que la principal oradora sería María Echarri, y de Manresa, con Dolors Monserdá, Véase para el primero, La Cruz de Castellón, 16-4-1910, La Voz de Valencia, 18-4-1910 y Nuevo Mundo, 28-4-1910. Para el mitin de Manresa, Feminal, n ${ }^{\circ}$ 35, 272-1910 y Nuevo Mundo, 24-2-1910.

10"La actuación femenina ha de orientarse preferentemente hacia el cuidado de la salud pública, de la beneficencia, de la cultura, de la moralidad en las costumbres, de la subsistencia y de la paz social". Salas de Jiménez, Juana, "Deberes que los Estatutos municipal y provincial imponen a la mujer española", en Tercera Asamblea de la Acción Católica de la Mujer. Crónica, Madrid, 1927, pp. 126-147.

11 Los estudios locales existentes sobre las elecciones de la Segunda República y la prensa confirman la intensa movilización y la propaganda desplegada por las mujeres conservadoras y católicas a través de agrupaciones partidistas y comités, que fueron más visibles que las desarrolladas por las mujeres republicanas y de la izquierda. Mercedes Yusta, "La Segunda República: significado para las mujeres", en Historia de las mujeres en España y América Latina, vol. IV: Del siglo XX a los umbrales del XXI, Cátedra, Madrid, 2008, 2a ed., pp. 101-122, esp. 112114. Véase también Pablo Villalaín Garcia, Mujer y politica. La participación de la mujer en las elecciones generales celebradas en Madrid durante la II República (1931-1936), Instituto de la Mujer, Madrid, 2000. 


\section{EL VOTO DE LAS MUJERES, UN ARMA POLÍTICA EN LA OFENSIVA CATÓLICA CONTRA LA REPUBLICA}

La concesión del voto femenino introdujo un elemento importante en la escena política española al ampliar considerablemente el censo electoral, lo que podía ser decisivo para decantar el resultado de una futura contienda electoral. Cómo señalaba la escritora socialista Victoria Priego, la captación del voto de las mujeres que convirtió en un objetivo político prioritario para todos los partidos:

\footnotetext{
“...Tenemos una mayoría casi aplastante. Podemos decidir, determinar el curso que ha de seguir España. Tenemos en nuestras manos la tremenda responsabilidad, el enorme peso del porvenir de toda la nación.

Todas las miradas fijas en nosotras. Todas las esperanzas, todos los temores y todas las ambiciones también. Y esto, fijaos bien, es lo más peligroso ¡Todas las ambiciones! ¡Cómo han de halagar esta fuerza numérica todos los partidos! ¡Cómo han de presentar ante nosotras todo género de atracciones, cómo tratarán de captarnos, de ofrecernos toda clase de felicidades humanas y aún divinas los ambiciosos del poder! ${ }^{12}$
}

Fueron las formaciones de la derecha católica las que recibieron con mayor entusiasmo la aprobación del sufragio femenino, ya que partian del convencimiento de que las mujeres, religiosas por naturaleza, asumirian el discurso de confrontación con el laicismo republicano, dando apoyo electoral a las formaciones confesionales y conservadoras ${ }^{13}$. De hecho, desde 1919 algunos periódicos y círculos católicos se habían mostrado partidarios de la ampliación del derecho de voto a las mujeres, destacándose especialmente en esta causa el diario El Debate ${ }^{14}$. En 1931, aunque algunos diputados católicos y tradicionalistas votaron en contra y también en el ámbito del feminismo católico se alzaron algunas voces contrarias ${ }^{15}$, la mayoría de la derecha consideró el sufragio femenino como un arma de combate en la cruzada católica contra la República. Con un sentido instrumental, como ya había ocurrido con la participación política femenina durante la dictadura de Primo de Rivera, se concebía en principio como un deber y, por extensión, un sacrificio para las mujeres conservadoras y católicas, que debían abandonar sus esferas "naturales" de actuación para luchar en un escenario completamente nuevo y que hasta entonces les había sido ajeno:

\footnotetext{
"Incorporada, de esta manera, la mujer a la política, no por afanes de notoriedad (...) así hoy se halla también dispuesta a defender su fe y su ideal contra los nuevos enemigos, si fuese preciso con la vida, porque sabe que no es sacrificio perdido el que se hace por Dios y por España"16.
}

12 Victoria Priego, La mujer ante las urnas, Índice, Madrid, 1932, pp. 22-23.

13 Ángel Luis López Villaverde, El gorro frigio y la mitra frente a frente: construcción y diversidad territorial del conflicto político religioso en la España republicana, Rubeo, Barcelona, 2008.

14 El Debate, 10-11-1919, 26-3-1920, 19-5-1920 y 13-8-1921. El discurso favorable al voto femenino se expresó también en revistas como España y América, El Iris de Paz, la Revista Católica de Cuestiones Sociales, Acción Femenina Católica y La Paz, vinculada, como el grupo Democracia Cristiana, a Severino Aznar.

15“¿Puede legalmente constituirse una sociedad en la que los hombres y las mujeres tengan los mismos derechos, las mismas obligaciones, se dediquen a los mismos oficios y tengan las mismas aspiraciones? Una sociedad cuyo fundamento legal sea éste, es una sociedad suicida (...) La mujer perfecta es la mujer del hogar, no la del mitin y el club..." Casilda de Antón del Olmet, Feminismo Cristiano, Imp. Juan Pueyo, Madrid, 1931, pp. 8-9 y 11.

16 Ellas, nº 68, 1-10-1933. 
Pero, aun considerándolo un deber ${ }^{17}$, para alguna de estas mujeres el participar de forma activa en el juego politico comenzaba también a ser un derecho irrenunciable, como reconocía Pilar Velasco, secretaria de la agrupación femenina de Acción Popular y, posteriormente, vicesecretaria del Consejo Nacional de la CEDA: “... tenemos que confesar que hay una gran dosis de justicia en la concesión de ciertos derechos a la mujer, ya que ésta, como colectividad y también como ser humano o individuo, forma parte de la sociedad y dentro de ella ha de desarrollar su personalidad"18. En una posición similar se encontraba otra de las más conocidas representantes de Acción Católica de la Mujer, Teresa Luzzatti, que afirmaba en la revista Ellas que "La mujer no está ni más ni menos capacitada que la mayoría de los hombres para la política"19. De igual forma se expresaba Juana Salas, una de las propagandistas que mejor sintetizó el concepto del feminismo católico y que ya en 1919 había defendido el sufragio femenino:

\begin{abstract}
"Hay que convencerse ... que la politica es la que gobierna: luego hay que meterse en ella, olvidando cuanto tiene de ingrato y pensando en cumplir un deber social (...) Van desapareciendo las prevenciones que había en España, creyendo que al actuar en el feminismo bastardearía la mujer su feminidad. Hubiera sido un gran daño; pero me voy convenciendo de que era vana esa preocupación que muchos abrigaban. Hasta ahora, sólo hemos trabajado en el campo social, tan en armonía con las actividades femeninas; pero observo que la política tampoco desnivela nuestro carácter"20.
\end{abstract}

Más contundente se mostraba una colaboradora de la revista Aspiraciones en un suelto publicado el 5 marzo de 1932:

\begin{abstract}
"La mujer española no está preparada para votar; y lo dice precisamente una mujer que tiene asiento en la Cámara ¿Quiere decirnos la Kent qué es lo que necesitamos para ello? ¿Una carrera? ¿Unos cursos universitarios? ¿O ser marimachos? Porque, en mi humilde opinión; no necesitamos más que dos cosas: tener voto $\mathrm{y}$ aprovecharlo...Damas católicas: ¡A demostrar que sin preparación podemos votar y que estamos dispuestas a defender nuestra fe, nuestro hogar y nuestra España, ¡dónde y cómo sea preciso!"21
\end{abstract}

No resultaba extraño que esas mujeres que venían militando en el campo del feminismo católico fueran las que reclamaron con más ahínco la participación activa en ese campo hasta entonces vedado para ellas: el de la "politica con mayúsculas", si bien es cierto que, en razón de las distintas opciones partidistas, se registraron distintas sensibilidades al respecto, pues en partidos como la Comunión Tradicionalista o Renovación Española parece que existir un mayor rechazo o autocensura hacia la mujer politica que en otros, como la CEDA o la Derecha regional Valenciana. Sin embargo, en el discurso que, sobre el ejercicio

17 El grado de aceptación a participar en el juego político presenta una escala de gradación entre las diversas asociaciones femeninas católicas y las formaciones políticas, que va desde un deber "temporal" que concluirá cuando se restablezca el orden católico en España a posiciones más igualitarias-. Véase, Rebeca Arce Pinedo, Dios, Patria Hogar. La construcción social de la mujer española por el catolicismo y las derechas en el primer tercio del siglo XX, Universidad de Cantabria, 2008, p. 176.

18 Ellas, no 7, 10-7-1932.
19 Ibid., n ${ }^{\circ} 2$, 5-6-1932.
20 Ibid., n ${ }^{\circ}$ 6, 3-7-1932.
21 Aspiraciones, n 8, 5-3-1932. 
pleno de la ciudadanía por parte de las mujeres, desarrollaron las distintas formaciones derechistas y que explica el rápido crecimiento de sus secciones femeninas, existe un punto de confluencia, ya que todas ellas consideraron la esfera política como un nuevo ámbito de actuación para el apostolado social y patriótico. Esto no era nuevo para las mujeres católicas, que lo habían venido practicando desde comienzos del siglo XX y sobre el que habian construido una identidad colectiva que se mimetiza ahora con su nueva identidad política. Este bagaje era fundamental, pero era necesaria la unidad de acción y una nueva organización, como reclamaba ya en 1931 Juana Salas desde las páginas de La Unión Católica-Femenina:

\begin{abstract}
"Pero lo inmediato, lo que acucia en estos momentos, es una organización grande, potentísima, donde quepan todas las que creen en Dios...Unámonos con intensa propaganda y despertemos al deber de ejercer el sufragio, no sólo como derecho, sino como un estricto deber social y religioso... Cuando se ataca a la Religión y a la Familia, cual se ataca en estos momentos, nuestro deber es defenderla con todos los medios que estén a nuestro alcance"22.
\end{abstract}

Pero ahora era necesario transcender el campo de la acción social para crear nuevas estructuras de encuadramiento político, nuevos instrumentos de propaganda y proselitismo, contando también con medios para la preparación de las mujeres ante el reto electoral. Esas serían las tareas que las mujeres católicas y conservadoras iban a emprender a lo largo de los años 1932 y 1933.

\title{
III. LA CONSTITUCIÓN DE LAS AGRUPACIONES POLÍTICAS FEMENINAS DE LA DERECHA CATÓLICA
}

En la nueva coyuntura política que se abría con la aprobación del sufragio femenino, la organización de una estructura partidista o asociativa específica para encuadrar políticamente a las mujeres y canalizar la propaganda y la movilización era un objetivo urgente. Como señalaba el Diario de Valencia, portavoz de la Derecha Regional Valenciana, había llegado la hora de salir a la calle y de "organizarse como mujeres amantes de nuestros deberes"23. Y en esa tarea, el largo aprendizaje en la organización de asociaciones propias desde comienzos de siglo y la capacidad de movilización de las mujeres católicas, que se habia intensificado de forma notable tras la proclamación de la República y los debates constituyentes en torno a la cuestión religiosa, aportaron un importante bagaje que facilitó una rápida organización política y electoral. Las peticiones a las Cortes, las manifestaciones devocionales o litúrgicas convertidas en actos propagandísticos de eminente carácter politico ${ }^{24}$, las conferencias especialmente dirigidas a las mujeres que se organizaron tanto en los partidos derechistas,

22 Juana Salas de Jiménez, "Sobre el voto femenino", en La Unión Católica-Femenina, n 79, 1931 , pp.5-6, p.6.

23 “Organización politica femenina ¡Ya llegó la hora!”, Diario de Valencia, 31-10-1931.

24 Con el triunfo de la República los católicos se movilizan de nuevo intensamente en la calle, dotando a los actos litúrgicos de un contenido político reivindicativo. Especial relevancia adquirió la celebración de festividades o ritos del fervor popular católico como el Corpus Christi, el Sagrado Corazón de Jesús y la devoción a Cristo Rey. Sobre la utilización politica de estas devociones, véase Antonio Manuel Moral Roncal, "Devociones para tiempos de espadas: El Sagrado Corazón de Jesús y Cristo Rey como categorias políticas del movimiento carlista (1931-1936)", Historia y Politica, no 21, 2009, pp. 219-246. 
como en las agrupaciones de Acción Católica de la Mujer, popularizaron el discurso de cruzada frente a la recién inaugurada República y animaron a la participación de las mujeres en ella, insistiendo en aquellas cuestiones que se consideraban más motivadoras y próximas a las inquietudes de las católicas como el ataque a la familia y la religión, la escuela única, el divorcio, o la igualdad jurídica de los hijos nacidos dentro y fuera del matrimonio ${ }^{25}$.

Las agrupaciones políticas femeninas católicas y conservadoras que se iban a formar desde finales del año 1931 y las campañas de propaganda electoral que a través suyo se canalizaron son el reflejo más claro de un intenso proceso de politización construido sobre un discurso coincidente en líneas generales con la defensa de la religión y de la patria -las consignas popularizadas por el movimiento católico femenino de los años veinte-, y el combate contra la política republicana, en especial la que hacia referencia al laicismo ${ }^{26}$. Sin embargo, dichas secciones femeninas no presentaban un carácter monolítico, sino que dentro del espacio político derechista existirá una diversidad en cuanto a su adscripción partidista concreta. Podriamos establecer una tipología entre aquellas que se configuraban directamente como secciones femeninas de los partidos políticos de derechas, como serían las de Acción Popular y de otros partidos regionales integrados en la coalición de la $\mathrm{CEDA}^{27}$, la Comunión Tradicionalista (las Margaritas) y Renovación Española, y aquellas otras agrupaciones o comités femeninos que, proclamándose apolíticos, se conforman bajo la tutela directa o indirecta de Acción Católica de la Mujer, como Cívica Femenina de Barcelona, la Acción Ciudadana de la Mujer de Valencia y la Acción Ciudadana de la Mujer de Sevilla, aunque alguna de ellas acabaría confluyendo con las Uniones de Derechas o la CEDA. A ellas se unirian también las secciones femeninas de los partidos nacionalistas conservadores como la Emakume Abertzale Batza del $\mathrm{PNV}^{28}$ y la Lliga Regionalista en Cataluña ${ }^{29}$.

25 Ejemplos de esas campañas de propaganda previas a la constitución de las agrupaciones femeninas lo tenemos en las organizadas por la Junta Diocesana de Acción Católica de la Mujer de Barcelona, en La Unión Católico Femenina, 80, 1931, pp. 1-2 y 123-15; Inmaculada Zayas de Rull, Conferencia dada en el Círculo de la Unión de Derechas de Palma de Mallorca a 9 de noviembre de 1931. Posición de la mujer católica ante la nueva Constitución española, Palma de Mallorca, Talleres Tipográficos Amengual y Muntaner, s.a.

26 A título ilustrativo, el lema de la revista Aspiraciones: "Defenderemos, hasta morir si es preciso, la Religión y la Patria". Este sería básicamente el eslogan de la propaganda de las agrupaciones femeninas derechistas. En este sentido, las continuas referencias a mujeres históricas como Isabel la católica o Santa Teresa de Jesús reforzaban el discurso de las mujeres como defensoras de la religión católica. Ellas también habían sido los modelos de referencia del feminismo católico en las dos primeras décadas del siglo XX.

27 Como la Unión Regional de Derechas gallega, la Acción Cívica de la Mujer de la Derecha Regional Valenciana, la Asociación Femenina de Educación Ciudadana de Salamanca, la Asociación Femenina Aragonesa o la Asociación Femenina Leonesa. Un listado de las secciones femeninas de Acción Popular por provincias en el Apéndice de la obra de José Monge nos da idea de la extensión y solidez del entramado de agrupaciones políticas femeninas vinculadas a Acción Popular y a la CEDA. Véase José Monge y Bernal, Acción Popular (Estudios de Biología Politica), Imp. Sanz Hermanos, Madrid, 1936, p.938 y ss. Un análisis de la evolución de las secciones femeninas de la CEDA entre 1931 y 1936, centrado en las provincias de Madrid, Sevilla y Toledo en Samuel Pierce, "The Political Mobilization of Catholic Women in Spain's Second Republic: The CEDA, 1931-6", Journal of Contemporary History, Vol 45(1), 74-94.

28 En este caso, la creación de secciones femeninas del PNV data de 1922. Desaparecieron durante la Dictadura de Primo de Rivera, pero renacieron con fuerza en 1931, Mercedes Ugalde, 
La constitución de las primeras agrupaciones femeninas fue casi simultánea en varias provincias, aunque cronológicamente la primera en formarse fue la Asociación Femenina de Educación Ciudadana de Salamanca ${ }^{30}$. Impulsado por Abilia Arroyo, el 24 de octubre de 1931 se celebraba en el Círculo Católico de Obreros un acto de propaganda con un aforo reservado exclusivamente para mujeres, en el que, tras los discursos de Gil Robles y Lamamié de Clairac, quedó constituida la agrupación. Esta se presenta como "asociación cívica femenina, que moviéndose por encima de los partidos políticos promueva la formación metódica y eficaz del entendimiento y voluntad de la mujer y la organice bajo los principios católicos, para su actuación política y social en la vida española”, una formula apartidista que facilitaba la unidad de diversas sensibilidades politicas en la misma agrupación ${ }^{31}$. En ese mitin de constitución se la despojó de un carácter religioso, remarcando su finalidad estrictamente politica para orientar el voto femenino hacia las opciones politicas de la derecha católica. Aunque preconizaba un talante independiente de los partidos políticos, su vinculación a Acción Nacional (Acción Popular desde el mes de abril de 1932) y a la CEDA era clara por la tutela directa que sobre ella ejercía Gil Robles.

Pocos días después, el 13 de noviembre, se constituía en Madrid la Asociación Femenina de Acción Nacional, que celebraría su primera Junta general el 17 de diciembre, si bien la iniciativa ya se había extendido a otras provincias, ya que a la Asamblea de Acción Nacional, celebrada a comienzos del mes de diciembre, asistieron 112 mujeres en representación de las asociaciones femeninas de la formación ${ }^{32}$. En esa primera Junta general se elabora el reglamento de la Asociación, que se constituye como una organización políticosocial, y se nombra la Junta directiva, de la que forman parte algunas destacadas militantes del feminismo católico y del entorno de Acción Católica de la Mujer, que tienen también relación familiar con miembros de la organización masculina, como Juana Salas, Mercedes Quintanilla, Mercedes Fernández Villaverde y Pilar Velasco que, como secretaria de la Junta, será una de las principales propagandistas de la agrupación, miembro del Comité Ejecutivo de Acción Popular y Vicesecretaria del Comité Nacional de la CEDA ${ }^{33}$.

Mujeres y nacionalismo. Génesis y desarrollo de Emakume Abertzale Batza. 1906-1936, Servicio editorial UPB, Bilbao, 1993, pp. 125-178.

29 Sobre la Sección Femenina de la Lliga Regionalista, se ofrecen algunos datos sobre su constitución en Josep Lluís Martín i Berbois, Ignoradas pero deseadas. La Mujer política durante las elecciones de la Segunda República en Cataluña, Icaria, Barcelona, 2015, pp.77-79. Un interesante estudio comparativo de las secciones femeninas de la Lliga y del PNV en Arnau Gonzàlez i Vilalta, "Mujer y nacionalismo conservador (1931-1936). Análisis comparado de dos casos: las Emakumes del PNV y la Secció Femenina de la Lliga Regionalista", Historia Contemporánea, $\mathrm{n}^{\circ}$ 31, 2005, pp. 623-647.

30 Un trabajo pionero sobre esa agrupación femenina en Mary Vicent, "The politicizacion of catholic women in Salamanca, 1931-1936", én Frances Lannon and Paul Preston (Ed.), Élites and Power in Twentieth-century Spain. Essays in Honour of Sir Raymond Carr, Clarendon Press. Oxford, 1990, pp.107-126.

${ }^{31}$ El Adelanto, 25-10-1931 y La Gaceta Regional, 26-10-1931. 205.

32 José Monge y Bernal, Acción Popular (Estudios de Biología Política), op. cit., pp.187, 192 y

33 Ibíd., pp. 205-206. Las catorce mujeres que conformaban la Junta habian sido propuestas por Gil Robles. En mayo de 1933, tras el surgimiento de la CEDA, se produjo una renovación de 


\section{Ilustración I. Sección Femenina de Acción Popular}

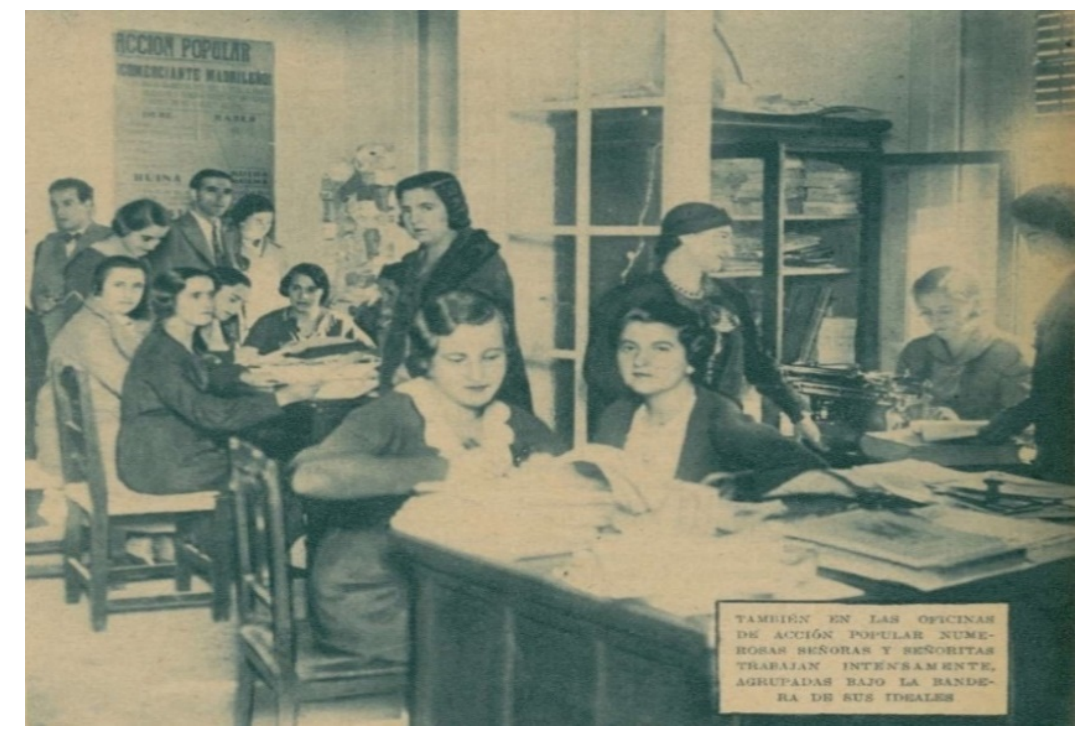

Pie de foto: También en las oficinas de Acción popular numerosas señoras o señoritas trabajan intensamente agrupadas bajo las banderas de sus ideales.

Fuente: Luis de Villalón "Cómo actúan los centros electorales madrileños". Artículo extraído de la revista Blanco y Negro del día 26 de noviembre de 1933. Sig.:1330/434.

Biblioteca Digital Memoria de Madrid (disponible en

http:/ / www.memoriademadrid.es/buscador.php?accion=VerFicha\&id=224231\&num_id=1\&num_total=8)

Paralelamente, en Valencia se daban los primeros pasos para la constitución de varias asociaciones de la derecha católica como la Sección Femenina de la Derecha Regional Valenciana (Acción Cívica de la Mujer) y las Margaritas tradicionalistas, a las que se suma como agrupación apolítica Acción Católica de la Mujer. El 13 de noviembre de 1931 se constituía en una Asamblea la Acción Cívica de la Mujer como "organización paralela a la de los hombres" dentro de la Derecha Regional Valenciana con el objetivo de encuadrar politicamente a las mujeres de la derecha porque, como resaltaba Luis Lucía, líder del partido, en su discurso ante la Asamblea constituyente "la organización política de la mujer, para ser eficaz debe ser eminentemente política, es decir, encuadrarse dentro de un partido político, única manera de que la acción del hombre y de la mujer respondan a una unidad de acción y de coordinación"35.

No obstante, aunque se hicieron llamamientos para que las todas las mujeres católicas se integrasen en una única organización conjunta que, para la Derecha Regional Valenciana, solo podría lograrse bajo la dirección de su sección Acción Cívica de la Mujer, lo cierto es que la unidad no pudo ser, ya que existían divergencias en cuanto al carácter partidista que debían tener dichas

\footnotetext{
la Junta, abandonándola aquellas no partidarias de las tesis accidentalistas. Véase José R. Montero, La CEDA. Catolicismo social y politico en la II República, Ediciones de la Revista de Trabajo, Madrid, 1977, vol. I, pp. 672-674.
}

34 Aunque en la fuente de referencia de la ilustración figura como procedencia la revista Blanco y Negro del día 26-11-1933, el artículo y fotografias del mismo aparecieron publicados en el número correspondiente al 12-11-1933.

35 Diario de Valencia, 14 de noviembre de 1931. 
asociaciones $^{36}$. En diciembre de 1931 Acción Católica de la Mujer impulsaba la creación de Acción Ciudadana de la Mujer Católica como asociación no vinculada orgánicamente a ningún partido político:

"Acción Ciudadana de la Mujer Católica nace sin compromisos con partido ni agrupación alguna preexistente. Queremos que nuestra vida política no esté mediatizada, sino que libremente refleje, a través del prisma del criterio católico, nuestra visión de los asuntos políticos (...) Debemos influir en los asuntos patrios, aportando un sentido de justicia (...) completando la obra de la justicia con la influencia de la caridad" 37

Siguiendo este mismo modelo apartidista, se constituyó en Castellón la Agrupación Católica femenina independiente, aunque finalmente esta asociación acabará integrándose en la Derecha Regional Valenciana en julio de 1933.38

Por su parte, las Margaritas valencianas también publicaron un manifiesto invitando a las mujeres católicas valencianas a adherirse a su agrupación para "ampliar" su acción de acuerdo con los nuevos derechos políticos concedidos a la mujer"39.

El 30 de noviembre se constituye la Acción Femenina Leonesa, ligada a Acción Agraria Leonesa y posteriormente vinculada a la CEDA. Su presidenta era Francisca Bohigas, que sería más tarde la única diputada de la derecha católica en las Cortes elegidas en noviembre de $1933^{40}$. El reglamento de la nueva agrupación, aprobado a finales de diciembre, insistía en que se trataba de una organización política, no religiosa, para orientar a la mujer en el nuevo campo que se le abre, pues "lo que ha de ser España lo hemos de decidir nosotros con nuestras papeletas los dias de elecciones"41.

En Zaragoza, el 19 de diciembre de 1931 la Agrupación Femenina Aragonesa también comienza su andadura, aunque no se constituirá formalmente hasta febrero de $1932^{42}$.

36 Isabel Morant Deusa i Rafael Valls, "Acció Cívica de la Dona, Sección Femenina de la Dreta Regional Valenciana (1931-1936”, Hometnage al Doctor Sebastià García Martínez, Consellería de Cultura, Educació i Ciència-Universitat de València, València, 1988, Vol. III, pp. 431-445, pp. 432-435.

37 Diario de Valencia, 29-12-1931.

38 Isabel Morant Deusa i Rafael Valls, "Acció Cívica de la Dona, Sección Femenina de la Dreta Regional Valenciana (1931-1936)”, op. cit., p. 433.

39 El Siglo Futuro, 16-12-1931.

40 Sobre Francisca Bohigas y la Acción Femenina Leonesa, véanse los trabajos de Juan Miguel Álvarez Domínguez: "Mujeres en politica durante la II República (Acción Femenina Leonesa a través de la prensa, 1931-1936)", Tierras de León, n ${ }^{\circ} 120$ y 121, Año XLIII, 2005, pp. 255-283 y "Francisca Bohigas, una diputada de derechas en la Segunda República", Historia 16, n 359 , 2006, pp.88-103. Véase también $\mathrm{M}^{\mathrm{a}}$ Concepción Marcos del Olmo, "Francisca Bohigas, militancia politica y actividad parlamentaria", en $\mathrm{M}^{\mathrm{a}}$ Concepción Marcos del Olmo; Rafael Serrano García (Eds.), Mujer y política en la España contemporánea..., op.cit,, Universidad de Valladolid, 2012, pp. 203-222.

41 “Acción Femenina Leonesa”, Diario de León, 2-1-1932. Citado en Juan Miguel Álvarez Dominguez: "Mujeres en politica durante la II República...", op. cit., p. 266.

42 Régine Illion, Mujer, politica y sindicalismo,1931-1936, Institución Fernando el Católico, Zaragoza, 2002, p. 29. 
Los primeros meses de ese año son de febril actividad para la constitución de agrupaciones femeninas por toda la geografia española, la mayoría de ellas vinculadas a Acción Popular, si bien muchas de ellas se reconvertirán en agrupaciones más amplias al integrarse en las coaliciones regionales denominadas Uniones de Derecha, como ocurre con la Sección Femenina de la Unión de Derechas de Palma de Mallorca o la Asociación Femenina de la Unión Regional de Derechas de Vigo ${ }^{43}$.

Al margen de las agrupaciones que giraban en torno a Acción Popular y, más tarde, a la CEDA, se situaron las secciones femeninas de los otros partidos de la derecha católica y monárquica, como la Comunión Tradicionalista y Renovación Española, que mantuvieron estructuras y funciones idénticas a las de Acción Popular ${ }^{44}$. La Sección Femenina Tradicionalista (Las Margaritas) existía en algunas provincias, en las que venía desarrollando labores benéficas y asistenciales a través de los círculos del partido ${ }^{45}$, pero desde finales de 1931 conocerán un notable desarrollo, adoptando una formulación política sin olvidar su tradicional función caritativa:

"Florezcan las Margaritas por toda España (...) sean ellas las primeras en la defensa del Templo y del Hogar, y, a ejemplo de nuestra nunca olvidada reina Margarita, practiquen la caridad, base de nuestra institución (...) Luchemos con el arma que la legalidad pone en nuestras manos para conseguir el triunfo de nuestra santa Religión y de nuestros amados Fueros"46.

43 En el caso de la asociación mallorquina, las orientaciones iniciales para su constitución fueron ofrecidas por Gil Robles en una visita realizada a Palma de Mallorca (Ellas, $\mathrm{n}^{\circ}$ 68, 1-101933, p. 8-9). En Vigo la asociación femenina tomó cuerpo en febrero de 1932, y en el mes de abril participaron en el primer mitin de la Unión de Derechas (Ellas, n ${ }^{\circ}$ 22, 23-10-1932, p. 5).

44 Ellas, no $50,7-5-1933$, p. 8 y n ${ }^{\circ} 54,4-6-1933$, p. 2.

45 Antonio Manuel Moral Roncal, "Mujer y carlismo durante la Segunda República: entre la actuación religiosa-benéfica y la acción politica”, en Manuel Álvarez Tardio; Roberto Villa García, Nuevos estudios sobre la cultura politica en la II República Española (1931-1936), Dykinson, 2011, pp. 89-104.

46 El Cruzado Español, 13-11-1931. 


\section{Ilustración II. Sección Femenina de "las Margaritas" tradicionalistas de Ondarroa (Vizcaya)}

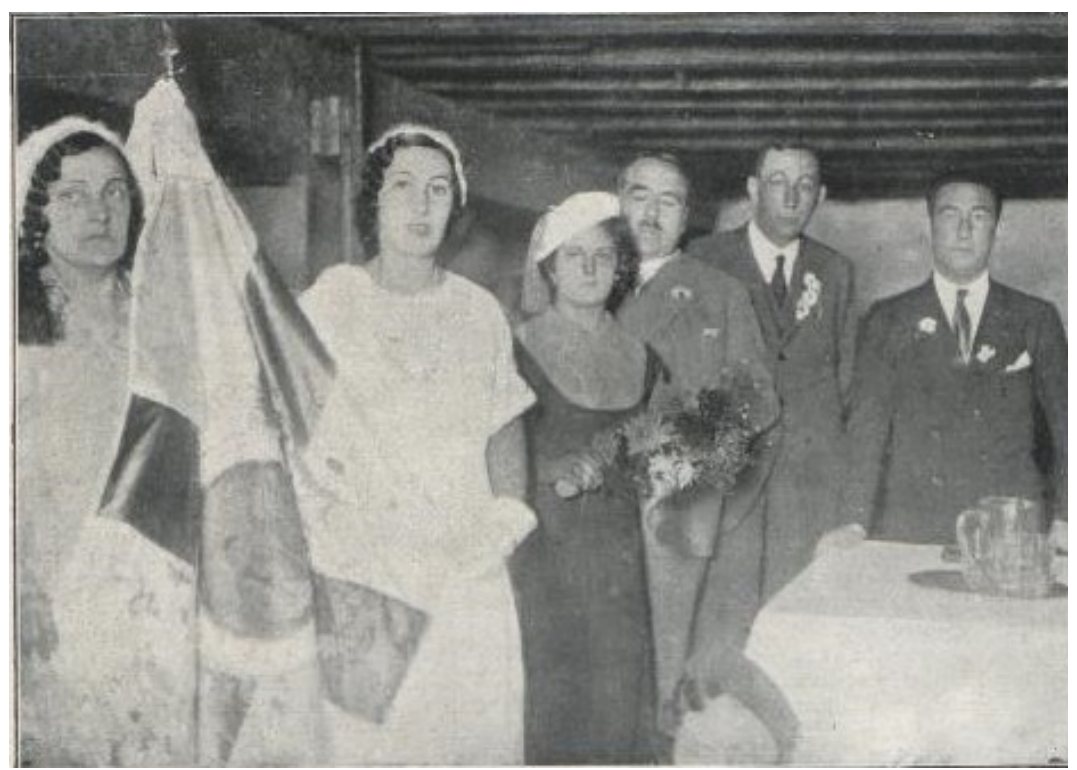

Pie de Foto: La nueva bandera de la agrupación feminista "Las Margaritas", bendecida antes de la Juntada y oradores que tomaron parte en la misma (Fot. Espiga).

Fuente: La Hormiga de oro. Ilustración católica, n 40, 5-10-1933 (Hemeroteca digital de la Biblioteca Nacional).

Se impulsará la creación de Agrupaciones de Margaritas por toda España, intentando lograr una coordinación nacional. En este sentido, en el mes de diciembre la agrupación madrileña de las Damas Católicas Tradicionalistas de Castilla hacía un llamamiento para constituir una formación conjunta confederada "teniendo en cuenta los actuales momentos y la intervención de la mujer en los asuntos públicos" 47 .

Por su parte, la Agrupación de Señoras de Renovación Española se formaba pocos meses después de la constitución del partido, tras su separación de Acción Popular. El 29 de abril se inauguraba el local de la asociación con un acto en el que intervendría Antonio Goicoechea. Como reconocían las dirigentes de la nueva organización su participación en política era "un mal necesario" con la finalidad de "unirnos todas las mujeres monárquicas de España"48. Al formarse el centro electoral de Tradicionalistas y Renovación Española (TYRE), las afiliadas a ambas formaciones constituirian una sección femenina común que se encargaría básicamente de la preparación y del reparto de la propaganda electoral ${ }^{49}$.

47 El Siglo Futuro, 16-12-1931. A la altura de 1933 contaban ya con una extendida red de asociaciones y se mostraron muy activas en la propaganda política, tanto en el País Vasco y Navarra como en otras ciudades españolas, en especial en Madrid. Ellas, $n^{\circ} 39,19-2-1933$, p. 7 y $\mathrm{n}^{\circ} 58,2-7-1933, \mathrm{p} .8$ y 11 .

48 Ellas, $\mathrm{n}^{\circ}$ 50, 7-5-1933, p. 8. Véase también la crónica de la inauguración de la agrupación en $A B C, 30-4-1933$.

49 Blanco y Negro, 12-11-1933, pp. 228-229. 


\section{Ilustración III. Comité Femenino de la TYRE}

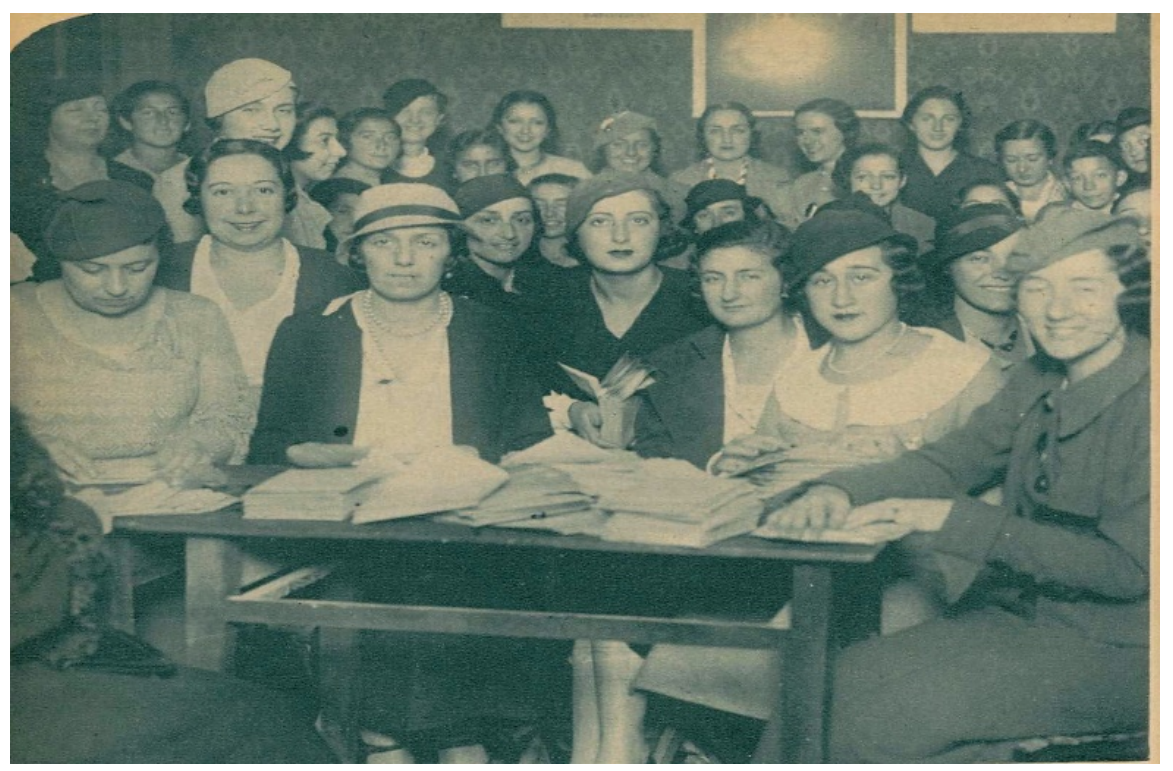

Pie de foto: En la "TYRE" (Tradicionalistas y Renovación Española) Las mujeres de una España que renace trabajan febrilmente, conscientes de su responsabilidad en los momentos actuales.

Fuente: Luis de Villalón, "Cómo actúan los centros electorales madrileños". Artículo extraído de la revista Blanco y Negro del día 26 de noviembre de 1933. Sig.:1330/4 50

Biblioteca Digital Memoria de Madrid (disponible en

http://www.memoriademadrid.es/buscador.php?accion=VerFicha\&id=224231\&num_id=1\&num_ total $=8$ )

El carácter independiente de las nuevas organizaciones femeninas preconizado fundamentalmente por algunos sectores de la jerarquía católica y por Acción Católica de la Mujer también alentará la creación de otra de las más potentes organizaciones femeninas del momento, la Acción Ciudadana de la Mujer de Sevilla. Inicialmente, la iniciativa parece más vinculada al tradicionalismo ya que el impulso original, como también había ocurrido en el caso de la Acción Femenina Leonesa, fue auspiciado por el político tradicionalista José $\mathrm{M}^{\mathrm{a}}$ Lamamié de Clairac, pero la asociación sevillana fue inclinándose politicamente hacia Acción Popular para acabar integrándose en la CEDA ${ }^{51}$. En otros casos, la existencia de estas asociaciones femeninas católicas independientes dificulta o retrasa la formación de otras agrupaciones políticas ligadas directamente a los partidos politicos. Este es el caso de Valladolid, donde la asociación de mujeres vallisoletanas católicas, tutelada por las formaciones politicas derechistas, impulsa en 1932 la Liga Anticomunista Femenina, que posteriormente adopta el nombre de Liga Anticomunista Española. Su desaparición a fines de 1934 dio paso a la configuración y activismo de las

50 Aunque en la fuente de referencia de la ilustración figura como procedencia la revista Blanco y Negro del día 26-11-1933, el artículo y fotografias del mismo aparecieron publicados en el número correspondiente al 12-11-1933.

51 Eloísa Baena Luque, "La mujer conservadora sevillana. Origen y actividad de "Acción Ciudadana de la Mujer", en Pilar Ballarin-Teresa Ortiz (eds.), La mujer en Andalucía. 1 er. Encuentro Interdisciplinar de Estudios de la Mujer, Universidad de Granada, 1990, Vol. I, pp. 329339, p.334. 
agrupaciones femeninas de Acción Popular, Renovación Española y la Asociación tradicionalista de Damas Margaritas ${ }^{52}$.

El modelo apartidista será también el seguido por la Cívica Femenina en Barcelona. El 5 de diciembre de 1931 la Junta Diocesana de Acción Católica patrocina una conferencia de Gil Robles en la que se plantea la necesidad de formar un frente único de la derecha católica y se insiste en la conveniencia de agrupar a las mujeres bajo la bandera católica. Aprovechando la solidez y extensión del asociacionismo femenino católico existente en la provincia, se constituye oficialmente la agrupación de Cívica Femenina en enero de $1932^{53}$. Es un ejemplo claro de fusión e integración de asociaciones femeninas impulsada directamente por la Acción Católica, con el objetivo de orientar el voto católico femenino, como señalaban en su manifiesto fundacional:

“...creemos que hoy más que nunca se hace necesario de todo punto (y precisamente con la existencia de esta multitud de organizaciones esporádicas y parciales que se presentan) constituir una organización aglutinante que, respetando las diferentes opiniones políticas, siempre respetables, de cada una, aúnen en apretado haz, a todas las que piensan en católico y cristiano (...) la nueva organización, sin ser la Acción Católica (que tiene vedado el campo puramente político) desea y quiere la adhesión de todas las mujeres católicas, aunque sin pedirles la renuncia de sus respectivos ideales, mientras militen y simpaticen con el espíritu del cristianismo.

Es más, la Acción Católica Femenina, solo reconocerá a esta nueva organización como la representante de la opinión católica organizada, y en la que llama a colaborar a todas las organizaciones parciales que merezcan por sus ideales y componentes una verdadera garantía de no buscar medros y ensalzamientos particulares, sino tan solo el triunfo de los derechos de la Iglesia y del verdadero bien del pueblo, utilizando las ventajas de la democracia y moviéndose dentro de las leyes justamente promulgadas, sin tender en modo alguno a derrocar regímenes, ni trastornar por sí misma los poderes constituidos".

A continuación, remarcaba su carácter apolítico y exponía los fines que perseguia:

“...no se adhiere a partido alguno, pero no combate tampoco a ninguno que admita los principios inmutables del catolicismo; quiere educar a la mujer, cualquiera que sea su posición, en los principios cívicos y sociales, preparar el censo femenino y vigilar su pureza al confeccionarlo oficialmente, disponiéndolas a todas a valerse del arma poderosísima del voto para encauzar la actual República española por derroteros de verdadero progreso social y cristiano..." 54 .

Como no fue posible crear una única agrupación femenina católica por la fragmentación política de las mujeres católicas conservadoras catalanas -que se dividieron en diversas agrupaciones como la Sección Femenina de Lliga Catalana, las señoras de la "Derecha de Cataluña" y las Margaritas Tradicionalistas"55-, la Cívica consideró necesario mantenerse para ayudar en la preparación electoral de las mujeres católicas, asegurando su independencia partidista hasta el final, al

52 Sonsoles Gómez Carbonero, Cultura ciudadana y socialización politica en la República. Actitudes y comportamientos de los vallisoletanos, Biblioteca Virtual Miguel de Cervantes, Alicante, 2002, pp. 381-384. Edición digital a partir del texto original de la tesis doctoral, disponible en http://www.cervantesvirtual.com/nd/ark:/59851/bmc3n234 (Consultada el 3-1-2018).

53 La Vanguardia, 10-4-1932.

${ }^{54}$ La Unión Católica-Femenina, n 81, 1932, pp. 11-12.

55 La Vanguardia, 25-X-1933. 
estar respaldada por Acción Católica de la Mujer de Barcelona. Un año después de su creación, la Cívica reconocía públicamente su fracaso en el objetivo de la unión de las mujeres católicas, pues "la experiencia demostró que la manera de apreciar el sentido de la derecha política era muy diversa", y recondujo sus objetivos a la orientación social y política general de las mujeres y a la verificación de la inscripción de las socias en el censo electoral. Sin identificarse con ningún partido concreto, organizaron también conferencias con oradoras y propagandistas de las diversas opciones de la derecha politica56.

\section{ORGANIZACIÓN Y ACTUACION DE LAS SECCIONES FEMENINAS}

\section{Modelo organizativo}

Independientemente de las adscripciones politicas, el formato organizativo de estas agrupaciones es muy similar y en la mayoría de los casos reproduce el de las secciones femeninas de Acción Popular. Se trata de secciones femeninas autónomas, separadas de la militancia masculina del partido, puesto que se trata de atraer a las mujeres en un ámbito nuevo de actuación motivándolas a partir de los problemas que consideran que les son propios. En opinión de Pilar Velasco, para contrarrestar los peligros de las "exageraciones feministas" y de "masculinización", convenía que las asociaciones sean autónomas y con equipos de dirección femenina: "para que la mujer desarrolle en ellas su personalidad, desenvuelva y perfeccione sus genuinas cualidades (...) estarán dirigidas por mujeres, gobernadas por mujeres, mujeres conscientes, dispuestas a no perder su feminidad por nada ni nadie" 57 . Además, una organización únicamente femenina contribuía a reducir los residuales recelos a la participación política, ya que remitía a un modelo ya conocido como era el que habían impulsado las asociaciones y sindicatos únicamente femeninos del catolicismo social. No obstante, la conexión y coordinación con el partido se mantuvo a través del tutelaje masculino en la posible figura de un asesor ${ }^{58}$ y en la integración de la sección femenina en la organización partidista matriz, como pone de relieve la estructura puesta en marcha en la Derecha Regional Valenciana y Acción Cívica de la Mujer, que contemplaba una reunión mensual de coordinación entre los comités directivos locales y provinciales y asambleas conjuntas de las dos agrupaciones. Además, en el Secretariado Político, cúpula del organigrama de la Derecha Regional Valenciana, se incorporaba una encargada de las relaciones con Acción Cívica de la Mujer ${ }^{59}$. José R. Montero en su estudio de la CEDA insiste en la subordinación de las secciones femeninas a los órganos centrales de la organización masculina del partido ${ }^{60}$, pero el análisis de la organización y actuación de sus agrupaciones femeninas matiza esta afirmación. De hecho, gozaron de una relativa autonomía, sujeta, no obstante, al control que propiciaba la estructura jerárquica vertical de los partidos derechistas, y que parece más acusado en el caso de las secciones femeninas Tradicionalistas y de Renovación

56 Ibid., 12-2-1933.

57 Ellas, no 8, 17-7-1932, p. 4.

58 Ibíd. En este artículo Pilar Velasco puntualizaba que "sus funciones serán consultivas, orientadoras e informativas, pero no podrá imponer su dictamen ni tendrá voto".

59 Derecha Regional Valenciana. Secretariado Politico, 1933, pp. 30 y 35-36.

60 José R. Montero, La CEDA. Catolicismo social y politico en la II República, op.cit, vol. I, p.676. 
Española. Además, aunque su presencia en el escaparate político del momento fuese menos visible que la de los militantes masculinos, desplegaron una intensa movilización y jugaron un papel fundamental en la captación de militantes y votantes, coadyuvando, sin duda, al éxito electoral de la derecha católica.

\section{Ilustración IV. Reunión de la Juventud Femenina de Acción Popular de Madrid}

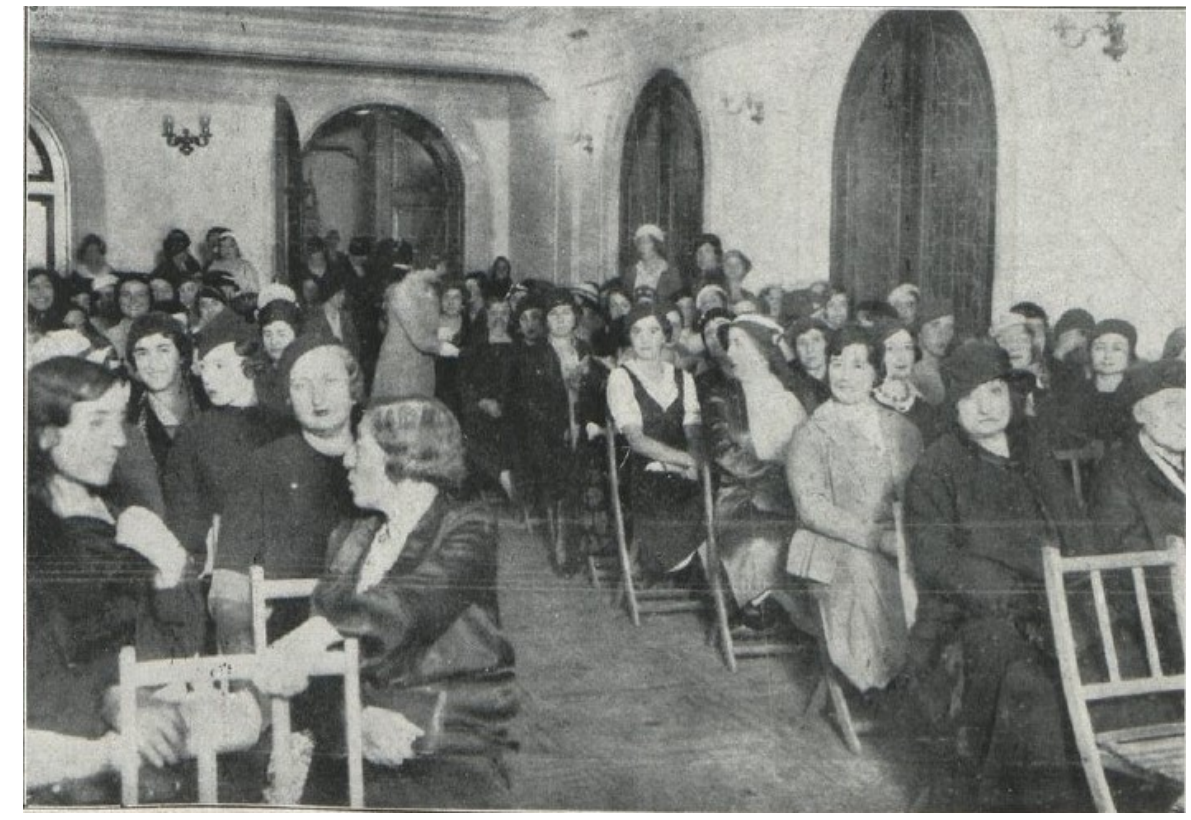

Pie de foto: Madrid: reunión celebrada por la "Juventud Femenina" de "Acción Popular" para tratar de los trabajos preparatorios para las próximas elecciones (Fot. Vidal).

Fuente: La Hormiga de oro. Ilustración católica, n. 43, 26-10-1933 (Hemeroteca digital de la Biblioteca Nacional)

El modelo organizativo que adoptaron es muy similar al que tenían las agrupaciones de Acción Católica de la Mujer, otra evidencia de la estrecha relación de las nuevas secciones politicas con las asociaciones femeninas confesionales, que en definitiva venian defendiendo los mismos valores conservadores y católicos desde comienzos del siglo XX. En sus primeros números, la revista Ellas explica este modelo de organización en una serie de artículos que, firmados por Pilar Velasco y con el significativo título de "Cómo organizar una agrupación política femenina", tenían el objetivo de que "la mujer española, consciente de la importancia que para el porvenir puede tener su voto, se disponga a ponerse en condiciones de ejercer bien y dignamente sus deberes de ciudadanía"61. En un primer artículo, la secretaria de la Agrupación Femenina de Acción Popular, tomando como ejemplo a las dos primeras agrupaciones de su partido, la Asociación Femenina de Educación Ciudadana de Salamanca y la Agrupación Femenina de Acción Nacional, daba instrucciones muy detalladas sobre el proceso de constitución de este tipo de asociaciones, su régimen interno, su técnica y organización electoral, con la finalidad de que se extendieran por todas las provincias y, en especial, en pueblos pequeños para conseguir ampliar

61 Ellas, $n^{\circ} 7,10-7-1932$. Otros artículos dedicados a la estructura interna de la agrupación y a las labores de propaganda aparecieron en los números correspondientes a los dias 17 y 24-7-1932. 
lo más posible el radio de influencia y propaganda y la captación de simpatizantes y afiliadas. Además, incluía un modelo de estatutos 62 y los procedimientos para legalizar la agrupación con indicaciones técnicas muy precisas como la relativa a no sobrepasar el número de 20 mujeres para formar el Comité organizador, porque si se superaba esa cifra habría que pedir permiso a la autoridad para celebrar la primera reunión.

Se ofrecía también el perfil ideal de las dirigentes de la nueva asociación, que debian ser personas conocidas y apreciadas en la localidad y "dentro del campo católico en que nos movemos, será fácil elegirlas entre las que se hayan distinguido al frente de Congregaciones piadosas, o trabajando en favor de la cultura, o en múltiples actividades religiosas y benéficas a que se consagra hoy la Acción Católica", procurando también que "pertenezcan a las distintas clases sociales, desde la encopetada aristócrata a la humilde obrera"63. El apostolado social femenino ofrecía un campo de actuación idóneo para las tareas propagandísticas ya que la intervención de las mujeres en la política era necesaria "no solo como elemento de combate, sino más aún como elemento de propaganda, de cohesión y de proselitismo"64.

Ese bagaje previo en las actividades vinculadas a las prácticas asistenciales y asociativas de las entidades católicas, que refuerza la idea de la retroalimentación entre Acción Católica de la Mujer y las agrupaciones políticas de la derecha católica, devino en un elemento fundamental a la hora de liderar las secciones femeninas de los partidos de derecha, como podemos comprobar también en la Junta directiva de la Sección Femenina de Renovación Española: "Señoras de gran prestigio social, de eficiencia y actividad admirables...con su vida de piedad cristiana, amor a la Patria y prácticas de beneficencia...todas tienen bien probado su valer en actividades benéficas, culturales y patrióticas"65. En el universo de la militancia católica femenina se imponía ahora un nuevo deber, el de la política, porque, como señalaba El Debate, era "la voluntad de Dios" y debía hacerse "con ese espíritu sobrenatural que, aun no tratándose de obras directas de Acción Católica (nosotros no hemos de mezclar a la Iglesia en las posibles equivocaciones de la política) inspira y seguirá inspirando siempre esencialmente las empresas de las mujeres católicas"66.

La relación de parentesco con los líderes o militantes de los partidos también fue fundamental en la elección de los cuadros directivos de las secciones femeninas de los partidos. La identificación de sus comités no deja lugar a dudas de las vinculaciones de tipo familiar que unen a estas dirigentes entre sí y a hombres de reconocida filiación derechista $\mathrm{y}$, con frecuencia, esto parece determinante para ejercer el liderazgo, como serian los casos de Abilia Arroyo o de

62 El reglamento de la Asociación Femenina de Acción Popular, que constituyó el modelo utilizado en las secciones femeninas derechistas, y hojas de propaganda para captar afiliadas en José Monge y Bernal, Acción Popular (Estudios de Biología Politica), op. cit., pp. 206-215. Otras agrupaciones adaptaron modelos de reglamentos similares a los del partido, que se configuraba como organización de militancia masculina, véase el folleto Derecha Regional Valenciana. Secretariado Politico, op. cit., pp. 63-66.

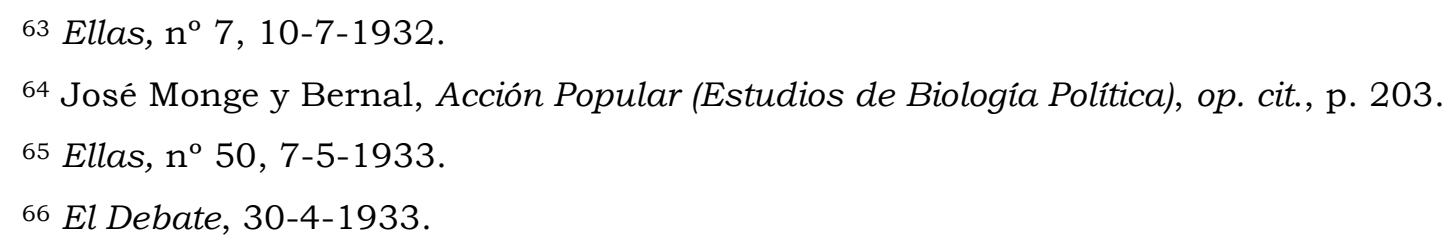


Juana Salas, que ilustran, además, la estrecha vinculación de las nuevas agrupaciones políticas con Acción Católica de la Mujer ${ }^{67}$. También es reseñable la integración de mujeres jóvenes con formación universitaria o carrera profesional como Pilar Velasco, licenciada en Filosofia y Letras; Francisca Bohigas, inspectora de educación; Pilar Careaga, ingeniera industrial, o María Rosa Urraca Pastor, licenciada en Filosofia y Letras e inspectora de trabajo ${ }^{68}$. El papel de estas propagandistas en las nuevas agrupaciones políticas femeninas $y$ en la propaganda y captación de afiliadas fue clave, como señalaba Teresa Luzzatti, “...es urgente despertad en la mujer el interés por los problemas que tan directamente la afectan. No es posible preparar de pronto a la masa, pero creo que sí lo sería formar a una elite de mujeres que a su vez emprendiese una intensa campaña para educar a la juventud femenina"69. De ahí, que gran parte de las agrupaciones femeninas impulsaran la creación de secciones específicas de juventud femenina que, como la de Acción Popular, se dedicaron a la formación doctrinal de las jóvenes como nuevas propagandistas, con el objetivo de "atraerse a la mujer obrera, que en gran parte ha abandonado a las organizaciones de derechas por no haber cumplido éstas y los católicos españoles los deberes que la justicia y la caridad cristiana imponian" 70.

67 Esa vinculación familiar también está presente en otras formaciones derechistas, como la Sección Femenina Tradicionalista dirigida por la esposa del líder de la Comunión Tradicionalista, la Condesa de Rodezno, o la Sección Femenina de Lliga Catalana, presidida por Francesca Bonnemaison, viuda Narcís Verdaguer Callis, dirigente de la Lliga Regionalista.

68 Este doble perfil sociológico y generacional es común también a la Sección Femenina de la Lliga Regionalista. Véase Susanna Tavera Garcia, "Sufragio, República y democracia de género en Cataluña, 1907-1936”, en Ángeles Egido y Ana Fernández Asperilla (eds.), Ciudadanas, militantes, feministas: Mujer y compromiso politico en el siglo XX, Eneida, Madrid, 2011, pp. 13-46, p. 33.

69 Ellas, $\mathrm{n}^{\circ}$ 2, 5-6-1932, p.2.

70 La Época, 5-5-1933. Los Estatutos de la Juventud Femenina de A.P. en José Monge y Bernal, Acción Popular (Estudios de Biología Politica), op. cit., pp. 218-221. 


\section{Ilustración V. Las propagandistas tradicionalistas y de Renovación Española}

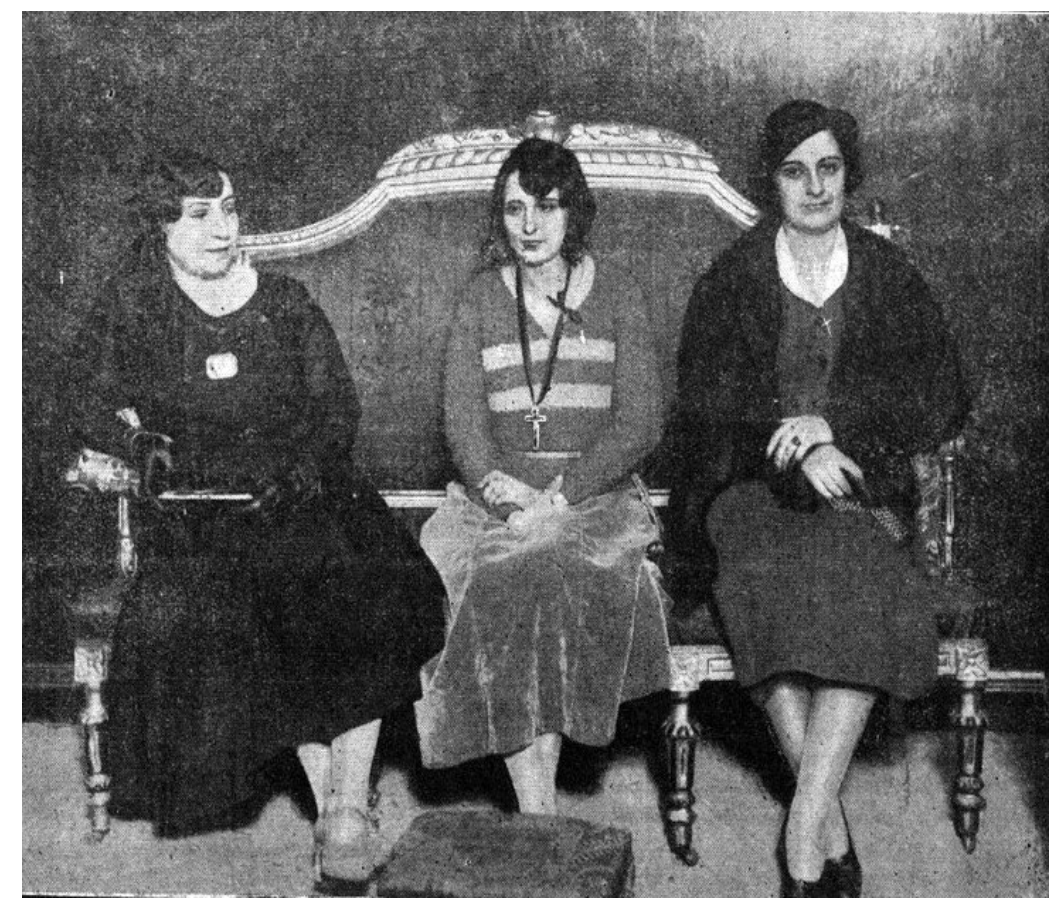

Pie de foto: "Juventud Triunfante: Las tres mujeres jóvenes que luchan en el mismo campo ideológico, y que se reunieron en ASPIRACIONES: Srta. Maria Urraca Pastor, Da ${ }^{a}$. Carmen Fernández de Lara y Srta. Pilar Careaga".

Fuente: Aspiraciones, $n^{\circ}$ 8, 5 de marzo de 1932, p. 1 (Biblioteca Nacional)

La prensa y alguna documentación dispersa permiten analizar los aspectos organizativos internos y las funciones de esas organizaciones políticas de las mujeres católicas y conservadoras, que presentan un esquema de funcionamiento muy similar, independientemente de su adscripción partidista concreta. Las que contaban con un modelo organizativo más depurado y también las más sólidas y eficaces eran las agrupaciones femeninas de Acción Popular ${ }^{71}$ - algunas de ellas formadas previamente como Secciones femeninas de Acción nacional o con otras denominaciones alternativas - y las de los partidos satélites y regionalistas coaligados con ella, como Acción Cívica de la Mujer de la Derecha Regional Valenciana, si bien dicho modelo fue adoptado también por las organizaciones de mujeres de otros partidos del espacio politico derechista.

El proceso de configuración de las secciones femeninas de Acción Popular y de otras formaciones políticas derechistas siguió un esquema muy similar en todas las capitales y en la mayoria de los casos fue impulsado directamente por el partido $^{72}$, tras la formación de las agrupaciones masculinas y siempre bajo su tutela a través de la dirección de los líderes locales. También se observa alguna excepción en la que el proceso es a la inversa, porque es la sección femenina la

71 Resulta indudable que era la sección femenina derechista mejor organizada en Madrid. Pablo Villalaín Garcia, Mujer y politica. La participación de la mujer en las elecciones generales celebradas en Madrid durante la II República, op. cit., p. 224.

72 Esa fue la tónica general, como reconocía la propagandista gallega Carmen Pita, cuyo concurso fue solicitado por los señores de la Derecha Regional Gallega (Ellas, 24-7-1932). 
base originaria del partido, llegando a ejercer en algún caso una mujer el liderato local hasta la constitución completa de la estructura partidista en la localidad ${ }^{73}$. Era frecuente la visita de alguno de los líderes derechistas del partido a nivel regional o nacional a la localidad en los momentos previos a la constitución de la sección femenina o para darle oficialidad una vez creada ${ }^{74}$. Las conferencias o charlas de diputados o personalidades del espacio politico derechista y católico explicando la importancia del voto femenino para la causa de las derechas, como la de Lamamié de Clairac en Sevilla, de Goicoechea en Valencia o de Santiago Guallar y Juana Salas en Zaragoza, coadyuvaron sin duda a la formación o expansión de estas secciones femeninas ${ }^{75}$. Tras la constitución de la agrupación en la capital, que se solemnizaba con un acto público, asamblea o mitin ${ }^{76}$, comenzaban las labores politicas de la sección femenina que, por regla general, se centraron en tres ámbitos de trabajo:
" $1^{\circ}$ Una parte política esencialmente intelectiva, dedicada al estudio, al conocimiento de la Verdad para dirigir y orientar.
$2^{\circ}$ Una labor de propaganda, principalmente emotiva y artística, que difunda la verdad bellamente y la haga amar; y
$3^{\circ}$ Una intensa obra social que, conociendo la Verdad y amándola, la siga y realice el Bien, con la práctica de la cristiana caridad" 77 .

Estos frentes de actuación se trasladaban a la estructura interna de la asociación que contaría con una secretaría técnica, encargada de la orientación politica general y de dirigir la propaganda, y una sección más técnica para el trabajo del censo. Esta última incluía una secretaría electoral, tantas vicesecretarias como distritos electorales existiesen y un organigrama muy elaborado para cada uno de ellos, con jefas de sección, una rectificadora por calles o grupos de viviendas $\mathrm{y}$, en las grandes ciudades, podría incorporar también a jefas de casa, que se ocupaban de la identificación de los vecinos de un edificio. De esta forma, la sección femenina de Acción Popular en Madrid, Acción Cívica de la Mujer en Valencia y la Agrupación Femenina Aragonesa contaron con una estructura de secciones o comités de distrito y barrios que les facilitaba la confección del censo electoral y las tareas propagandísticas que desarrollaron en

73 Como fue el caso de Mercedes Sánchez Arrieta en la CEDA de Lugo. Cit. en Emilio Grandío Seoane, "CEDA: movilización católica y democracia", en Francisco Morente; Jordi Pomés, Josep Puigsech (Eds.), La rabia y la idea. Politica e identidad en la España republicana (1931-36), Prensas de la Universidad de Zaragoza, 2016, pp. 121-146, p. 130. Otro ejemplo lo tenemos en Acción Popular de la Mujer de Las Palmas de Gran Canaria, cuya constitución es anterior a la del partido. José Monge y Bernal, Acción Popular (Estudios de Biología Politica), op. cit., p.1019. La creación de la sección femenina como núcleo originario de la estructura local del partido en la localidad fue más frecuente en pequeñas localidades y pueblos.

74 Este fue el caso de la Sección Femenina de la Unión de Derechas de Palma de Mallorca (Ellas $\mathrm{n}^{\circ}$ 68, 1-10-1933, p. 8-9) o de la Asociación Femenina de Educación Popular de Salamanca (La Gaceta Regional, 26-10-1931)

75 La Unión, 11-12-1931(Cit. en Eloísa Baena Luque, "La mujer conservadora sevillana. Origen y actividad de "Acción Ciudadana de la Mujer", op. cit., p. 3329. Para Zaragoza y Valencia, véase El Noticiero, 14-2-1932 y Diario de Valencia, 13-4-1932.

76 A título de ejemplo, los celebrados por la Asociación Femenina de Educación Popular en Salamanca (La Gaceta Regional, 26-10-1931) y Acción Civica de la Mujer en Valencia (Diario de Valencia, 14-11-1931)

77 Ellas, no 8, 17-7-1932, p. 4. 
los meses previos y durante la campaña electoral78. En el caso de Madrid, los centros de barriada de la CEDA estaban configurados dentro del organigrama partidista como sucursales para la asistencia social del partido ${ }^{79}$, tarea que dentro de la diferenciación sexual de funciones existente en el partido era propia de las secciones femeninas y que se utilizaba como moneda de cambio para contrapartidas electorales. De forma paralela, se acometía la organización en los pueblos de la provincia, un objetivo prioritario para expandir territorialmente las agrupaciones y captar nuevas militantes. A ellas se dirigían las propagandistas de la capital bien por iniciativa propia, bien por petición expresa de algunas señoras de la localidad, celebrando reuniones y actos de propaganda y prestando su ayuda para la constitución legal de estas secciones locales, siendo muy frecuente que se animaran estos actos con coros y trajes regionales. Es de resaltar que el activismo desplegado en este campo de actuación permitió a estas secciones vinculadas a Acción Popular y a la CEDA una expansión geográfica muy rápida y contar en pocos meses con unas extensas organizaciones provinciales ${ }^{80}$.

Para la construcción de la organización provincial, las secciones femeninas de Acción Popular debian hacer primero un completo estudio de cada pueblo (datos estadísticos y geográficos, datos religiosos y datos sociales, fuerzas politicas que dominan, ambiente general en lo politico y en lo social). Una segunda tarea consistía en la confección de un fichero de Asociaciones politicas de derechas, con la conveniente división entre masculinas y femeninas, en el que constaran los nombres de la entidad, presidente, secretario y número aproximado de asociados. También se elaboraba otro fichero de direcciones de personas influyentes en cada localidad, "con la anotación de A. (adicto), C (contrario), I. (indiferente) y todas las noticias que convengan respecto a su historial y sus relaciones con nuestra organización"81.

En el transcurso del primer año de su constitución, las agrupaciones femeninas solían celebrar una asamblea de carácter provincial que, además de exponer el trabajo realizado hasta entonces y elegir o ratificar los cargos directivos, constituía un gran acto de afirmación propagandística, con discursos e intervenciones de destacadas propagandistas y líderes políticos nacionales. Podría servir como ejemplo la Asamblea de la Agrupación Femenina Aragonesa celebrada en Zaragoza en febrero de 1933. En ella se presentaron ponencias

78 Para la Agrupación Femenina Aragonesa, véase El Noticiero, 21-2-1933. En el caso de Valencia, Acción Cívica de la Mujer celebró numerosas reuniones, conferencias y pequeños mítines en cada uno de los distritos durante la campaña electoral (Diario de Valencia, 2 y 5-111933).

79 José R. Montero, La CEDA. Catolicismo social y politico en la II República, op.cit, vol. I, p.380.

80 Un año después de su constitución la Agrupación Femenina Aragonesa contaba en febrero de 1933, cuando se celebra su I Asamblea, con 118 agrupaciones constituidas en los pueblos de la provincia de Zaragoza. Véase El Noticiero, 21-2-1933. En Valencia Acción Civica de la Mujer en Valencia tenía 291 agrupaciones locales en julio de 1933 (Derecha Regional Valenciana. Secretariado Politico, op. cit., p.88). Las cifras de afiliación de las distintas agrupaciones son elevadas, aunque hay que tomarlas con precaución ya que proceden de la prensa afin y pueden estar magnificadas. En todo caso, aunque se relativicen estas cifras, lo cierto es que las secciones femeninas podian alcanzar al menos el cuarenta por ciento del total de afiliación de las agrupaciones locales, constituyendo una evidencia del importante activismo politico que desplegaron.

81 Ellas, no 8, 17-7-1932, p. 4. 
sobre organización (que incluía la organización local, provincial y del censo femenino), propaganda y prensa, juventud femenina y obras sociales ${ }^{82}$.

\title{
2. Formación politica y control del censo electoral
}

Las ponencias que se presentaban en las Asambleas de las secciones femeninas y en las asambleas generales de Acción Popular o de la CEDA constituyen un claro reflejo de los frentes de actuación de estas agrupaciones. El primero de ellos, que constituyó la finalidad primigenia de las mismas, es la formación de las mujeres para el ejercicio pleno de la ciudadanía política:

\begin{abstract}
"aunque ello es importantísimo, no toda la actividad politica femenina ha de reconcentrarse en lo electoral, o sea en la preparación y organización para las posibles futuras elecciones. Es preciso también dar a la mujer española unas claras y someras lecciones sobre lo más fundamental de nuestro gran ideario político tradicional y español, e instruirla sobre las modas y formas con que ella puede contribuir a la difusión, propaganda y triunfo de ese ideario. Hay que ganar, primero, unas elecciones. Convenido. Pero hay que saber, también, qué España es la que quisiéramos hacer el día en que, ganadas esas elecciones, pudiéramos ser artífices del futuro"83.
\end{abstract}

Todas las secciones femeninas de los partidos derechistas dedicaron gran parte de su tarea a informar a las mujeres de la nueva situación política y de sus derechos a través de la prensa y de la organización de ciclos de conferencias, que adoptaron el formato de los círculos de estudios que utilizaban las asociaciones de Acción Católica de la Mujer, que también dedicó gran parte de estos cursos a la preparación electoral de las mujeres. En principio, las temáticas escogidas fueron de carácter general, como la nueva Constitución y la legislación laica republicana, con especial insistencia en la cuestión del divorcio y la escuela única republicana. Se trataba de una formación política primaria, como la ofrecida en las conferencias organizadas por Acción Católica de la Mujer en Barcelona en los últimos meses de 1931, porque las mujeres católicas "poseedoras estas del derecho al voto...y conscientes de su derecho deben entrar en este campo de las ideas, con el bagaje de la cultura y la formación sólida, propia de las personas conscientes e inteligentes..." 84 .

A medida que se acercaban las elecciones, se fueron organizando otras conferencias de temática más concreta y cursillos de carácter más técnico y dirigidos directamente a la práctica electoral y al ejercicio del voto, como los organizados por la Cívica Femenina de Barcelona en mayo de 1933 que, con un formato de taller con el significativo título de "Des de la Llar al Parlament", incluian una serie de 6 lecciones para la preparación electoral de sus asociadas: La suprema conquista del feminisme espanyol, Els drets constitucionals, En torn del sufragi; Técnica electoral, La propaganda politica y La formació política ${ }^{85}$. En el

82 Una amplia reseña de la Asamblea en El Noticiero, 21 y 22 de febrero de 1933. La Asociación Femenina de Educación Ciudadana celebró una asamblea similar en noviembre de 1932 . La Gaceta Regional, 28-11-1932.

83 José María Pemán, "Votos e ideas", Ellas, n 1, 29-5-1932, p. 6.

${ }^{84}$ La Unión Católico-Femenina, $\mathrm{n}^{\circ}$ 80, 1931, p. 1-2. Un breve resumen de los temas tratados en las conferencias en las páginas 13-15 del mismo ejemplar.

85 Vida Católica Femenina, n 90, mayo de 1933, p. 5. 
local del Comité de la TYRE se impartieron también sesiones formativas prácticas para interventores y apoderados a los que asistieron también las mujeres de los dos partidos que integraban el comité electoral ${ }^{86}$. Fueron éstas prácticas comunes en todas las asociaciones femeninas derechistas e incluso llegó a publicarse un folleto de instrucciones específicas para las mujeres católicas ¿Y vosotras? (manual de la electora católica) ${ }^{87}$.

Otra de las tareas de las secciones femeninas fue la elaboración del censo electoral femenino, una labor que para muchas de ellas no era totalmente nueva, porque Acción Católica de la Mujer ya había trabajado en ello durante la dictadura de Primo de Rivera. En febrero de 1932 la asociación "Aspiraciones" publicaba anuncios en su revista para que las mujeres se acercasen a su local para realizar su inscripción en el censo electoral: "Se ruega a toda mujer, de la clase social que sea y de ideas políticas diversas (a ninguna hemos de preguntarle), que pasen a inscribirse, no importando que sea dia festivo ni hora, pues constantemente hay asociadas que llenan las hojas"88.

\section{Ilustración VI. La inscripción en el censo electoral}

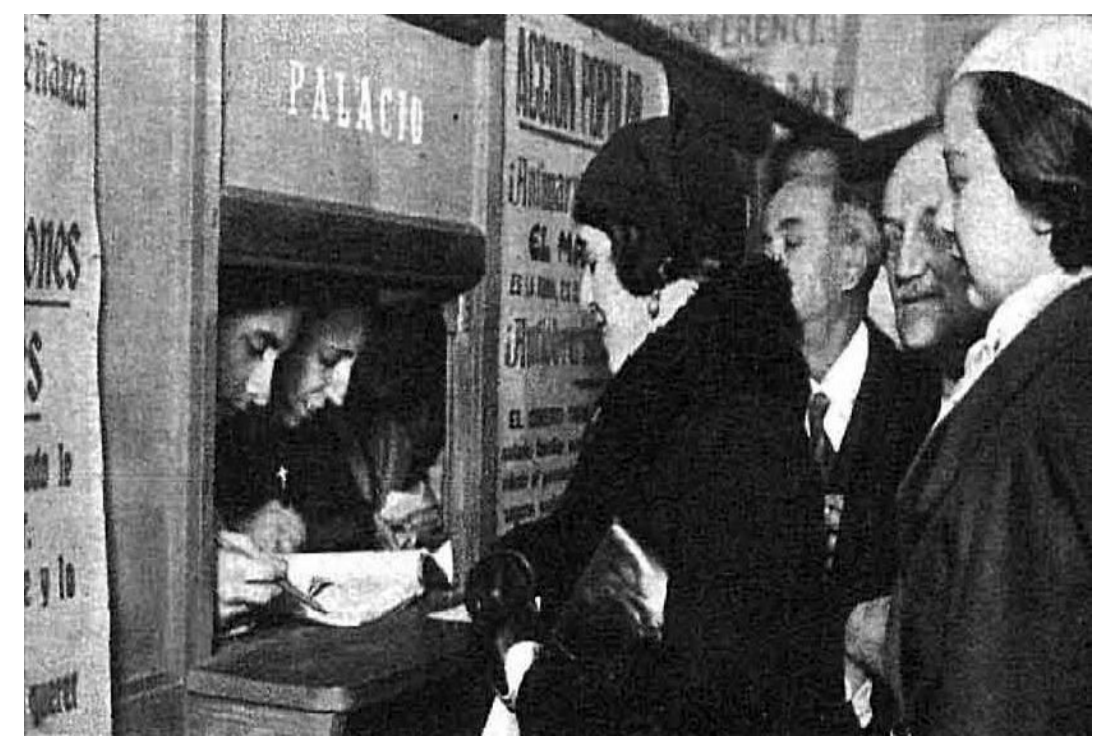

Pie de foto: Ante la ventanilla de Acción Popular correspondiente al Distrito de Palacio, una presunta votante de las derechas consulta su inclusión en el Censo. Fots. Cortés.

Fuente: Nuevo Mundo, 17-11-1933 (Hemeroteca digital de la Biblioteca Nacional)

Ante la novedad de la participación femenina en política, las crónicas periodísticas dejaron testimonio de la intensa actividad que en el control del censo realizaban estas agrupaciones femeninas de los partidos derechistas, como

86 Blanco y Negro, 12-11-1933.

87 En las semanas anteriores a las elecciones se publicaron anuncios de la venta del folleto titulado ¿Y vosotras? (manual de la electora católica). ABC, 26-10 y 7-11-1933.

88 Aspiraciones, $\mathrm{n}^{\circ}$ 6, 20-2-1932, p. 15. La Cívica Femenina también incluyó anuncios en la prensa local para que las mujeres acudiesen a sus locales a asesorarse para realizar su inscripción en el censo electoral, La Vanguardia, 5-3-1933. 
la que publicaba $A B C$ sobre la Asociación Femenina de Renovación Española a escasos días de las elecciones:

\footnotetext{
"Es aquí donde se confecciona y rectifica el Censo. Una dama de sienes plateadas anota nombres (...) se acerca una muchacha de aire desenvuelto y andar firme. Y al momento:

-Está usted en el distrito del Centro. En aquella mesa la informarán- contesta la dama de plateadas sienes.

En la mesa señalada, una muchachita fina y espigada, de grandes ojos de gacela. E1 dialogo es breve.

-Vivo en Alcalá-, 25. Estoy incluida en la lista. Debo votar...

-En la sección 32 del Centro.

Sorprendida ante esta prontitud en las respuestas, que me hace ver lo bien preparadas que están estas muchachas, me acerco.

-Supongo que es la primera vez que actúa en estas cosas, ¿no?

-Naturalmente. Pero esto es sencillísimo. Lo que ocurría es que los hombres se empeñaban en mostrarnos estas cosas como verdaderos problemas algebraicos ¡Con lo fácil que es! ¡Tontísimos...! -termina con una alegre sonrisa." 89
}

Además de facilitar a las nuevas votantes las tareas de inscripción en el censo e informar de las mesas de votación, también realizaron tareas de depuración del censo electoral general y de identificación política del cuerpo electoral, con el fin de calibrar la influencia de las fuerzas de derecha por barrios, distritos y localidades, como relataba esa misma militante de la Asociación Femenina de Renovación Española: “...vamos por las casas, enterándonos del ideario político de los que allí viven. Los muertos los señalamos con una cruz, con una raya roja los republicanos y los de derechas con esta azul"90. Cooperación inestimable fue también la escritura de sobres, empaquetados de candidaturas y manifiestos y el reparto de propaganda, para lo que se reclutaban voluntarias, a veces a través de anuncios en la prensa ${ }^{91}$.

\footnotetext{
89 ABC, 7-11-1933.

90 Ibídem.

91 "Cada sobre, cada candidatura y cada manifiesto ha pasado por una mano femenina", Blanco y Negro, 12-11-1933.
} 


\section{Ilustración VII Organización de un fichero electoral}

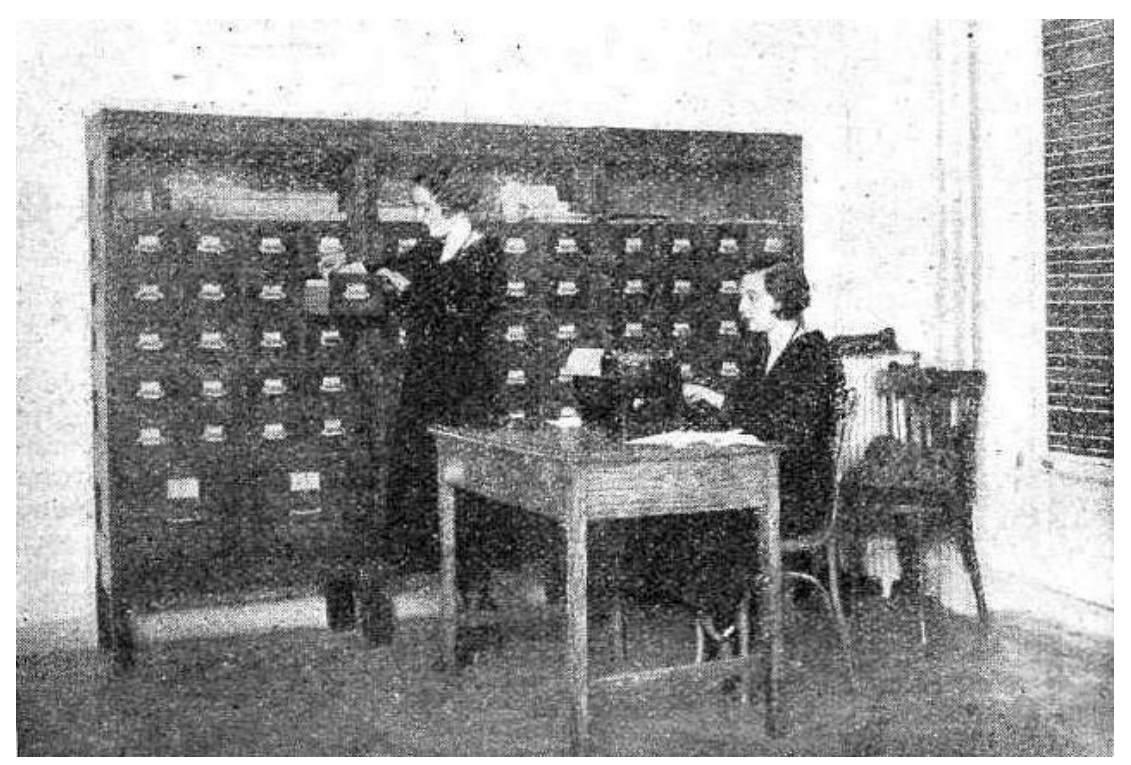

Pie de foto: Organizando un fichero electoral.

Fuente: Ellas. Semanario de las mujeres españolas, n 8, 17-7-1932, p. 4 (Hemeroteca digital de la Biblioteca Nacional)

\section{Propaganda y prensa}

A las campañas de propaganda de la derecha política se incorporaron también con gran entusiasmo las mujeres que integraban las secciones femeninas, utilizando diversos métodos y contando para ello con el aliento de los lideres derechistas, como Gil Robles o el conde de Vallellano ${ }^{92}$. Pilar Velasco publicó en la revista Ellas unas orientaciones sobre la propaganda en sus artículos sobre las agrupaciones politicas femeninas. Incluía una clasificación de las tareas de propaganda hablada y escrita que debian realizarse. Las primeras y más inmediatas eran las visitas a domicilio, que permitían la identificación política y una comunicación propagandística más directa. En un segundo nivel, se situaban las conferencias en los círculos de estudio o las sedes de las asociaciones, que podian ser cerradas para las asociadas o abiertas para captar nuevas afiliadas. Por último, el mitin, que era el acto de propaganda por excelencia y el que por vez primera situaba a las mujeres en la tribuna pública y en el gran escenario de la politica ${ }^{93}$.

92 Este último consideraba que "La intervención de la mujer en la política no sería efectiva si no recurriese al proselitismo de la oratoria", Ellas, $\mathrm{n}^{\circ} 1,29-5-1932, \mathrm{p} .7$.

93 Ellas, n. 9, 24-7-1932, p. 6. 


\section{Ilustración VIII. Las oradoras del mitin de Acción Cívica de la Mujer (Valencia, 10 de junio de 1932)}
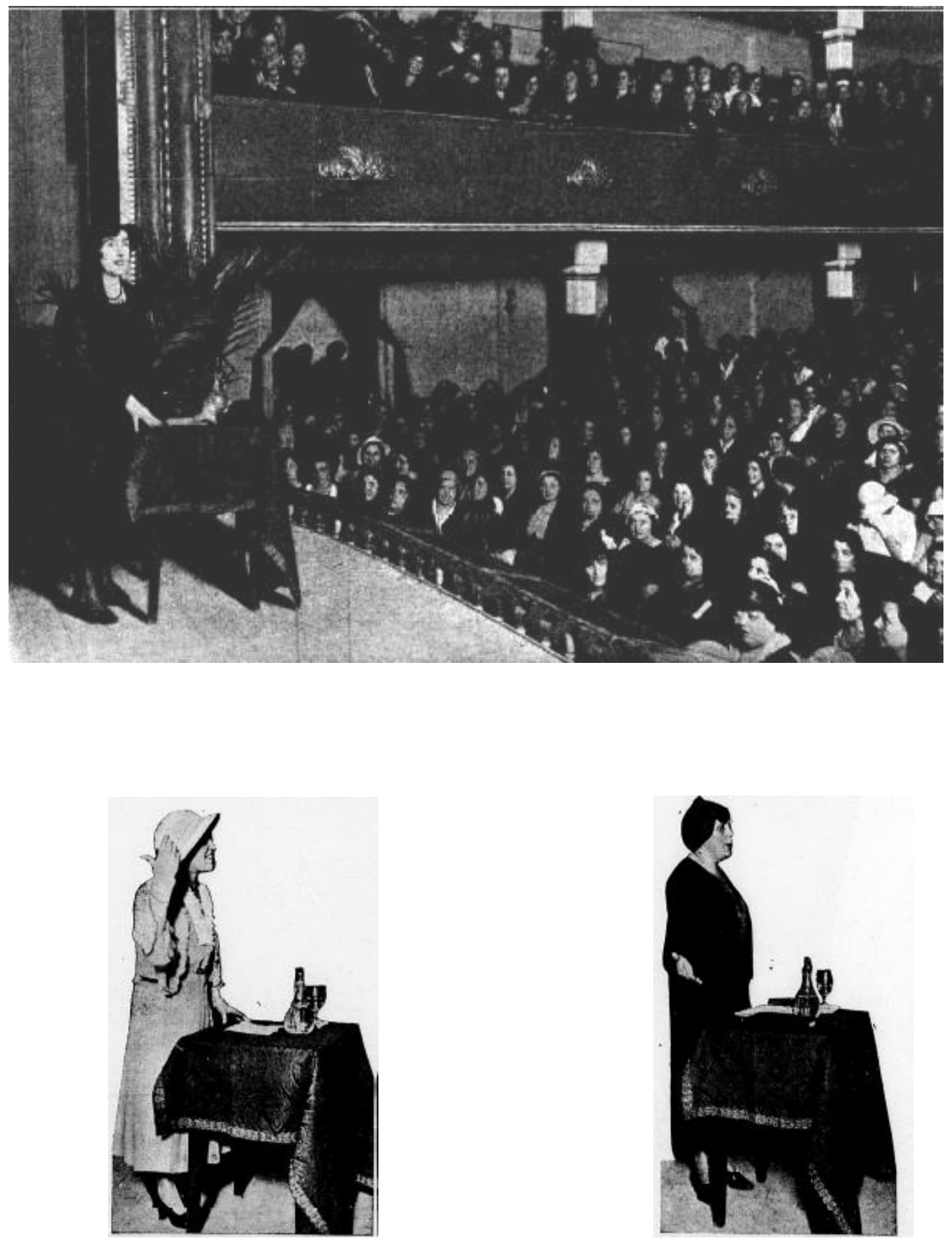

Intervenciones de Pilar Velasco, secretaria de Acción Popular de Madrid; Leonor Maldonado, de

"Acción Cívica de la Mujer" de Valencia y de Abilia Arroyo de Román, Presidenta de la "Asociación Femenina de Educación" de Salamanca en el mitin de Acción Cívica de la Mujer celebrado el 10 de junio de 1932.

Fuente: Ellas. Semanario de las mujeres españolas, n 5, 26-6-1932, pp. 8-9 (Hemeroteca digital de la Biblioteca Nacional) 
La organización de mitines femeninos fue una de las constantes de esa irrupción de las mujeres en la escena pública y no rehuyeron el desafio, porque se veían capaces de emprender una tarea de más relevancia que la de la confección del censo94 y porque, tanto los partidos como ellas mismas, consideraban que era mejor la comunicación entre mujeres. Fueron frecuentes los mítines en los pueblos con oradoras femeninas y a los que solo se permitía la entrada de mujeres, si bien las más destacadas propagandistas participaron en grandes mítines femeninos como los celebrados por Acción Cívica de la Mujer en Valencia en junio de 1932 y en junio de 193395. Algunas de las principales oradoras de los partidos derechistas recorrieron la geografía española dando mitines en solitario o compartieron tribuna con los dirigentes masculinos en los grandes mítines nacionales como Pilar Careaga, de Renovación Española96; las cedistas Pilar Velasco ${ }^{97}$ y Francisca Bohigas -esta última participó, junto a Gil Robles y Luís Lucia, en el multitudinario mitin del Monumental Cinema de Madrid en febrero de $1933^{98}$-, y la tradicionalista Urraca Pastor, que impartió numerosas conferencias por toda España ${ }^{99}$. En los partidos derechistas, el papel de estas mujeres propagandistas y oradoras se reservaba especialmente a aquellas mujeres sin cargas familiares para que no hubiera incompatibilidad entre la actividad política y el cuidado del hogar y de los hijos, si bien este se podía combinar con una actuación femenina más pasiva a través del voto, la prensa y la decisiva influencia que pudieran ejercer en el ámbito familiar. Por el contrario, "la mujer soltera o viuda y la madre cuyos hijos ya no necesitan de sus cuidados (...) deben actuar en la tribuna, en los cabildos municipales, en el Parlamento; han de hacer politica de acción hasta donde les permitan sus dotes naturales, su cultura y su talento"100 .

94 Así lo reconocieron las afiliadas a la Asociación Femenina de Acción Popular de Murcia, que solicitaron al partido intervenir en la propaganda oral por los pueblos. Véase Memoria de la Asociación Femenina de Acción Popular, leída en Junta general celebrada el 15 de mayo de 1933, Imp. De Miguel Arenas, Murcia, p. 4.

${ }^{95}$ Las reseñas de los actos, que congregaron a un numeroso público y en los que participaron, además de las dirigentes valencianas, Pilar Velasco en el de 1932 y Francisca Bohigas en el de 1933, en Diario de Valencia, 12-6-1932 y 24-6-1933.

96 ABC, 18-3-1932 y 18-6-1933.

97 Ibid., 26-7-1932 y 4-2-1933.

98 El Debate, 7-3-1933. La prensa se hizo amplio eco de este mitin, valorando muy positivamente la oratoria de Francisca Bohigas.

${ }_{99}$ El 5 de marzo de 1933 Urraca Pastor impartió una conferencia pública en el cine Ópera que fue reseñada ampliamente en el $A B C, 7-3-1933$ y publicada después como propaganda impresa. Conferencia pronunciada en el 'Cine' de la Opera, el domingo, dia 5 de marzo de 1933, por la señorita María Rosa U. Pastor. Información publicada por "El Siglo Futuro", s.a. Su trayectoria como propagandista, en Antonio Manuel Moral Roncal, "María Rosa Urraca Pastor: de la militancia en Acción Católica a la palestra política carlista (1900-1936)", Historia y Política, n 26, 2011, pp. 199-226.

100 Acción. Defensor de los intereses de la Mujer, Gijón, 12-3-1932. 


\section{Ilustración IX. Un mitin femenino tradicionalista en el Teatro Calderón de Valladolid}

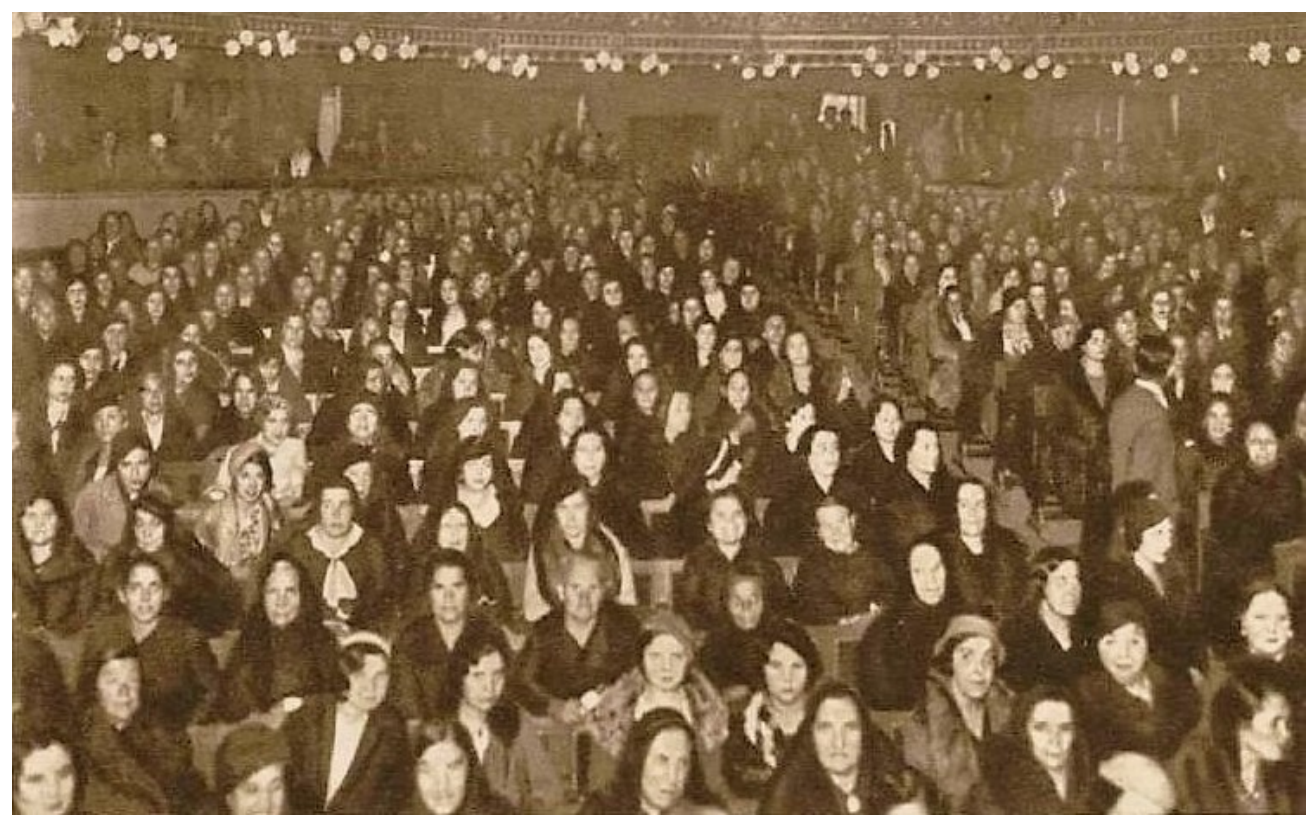

Fuente: “iMujeres, a votar!" Artículo extraído de la revista Estampa del 22 de abril de 1933.

Signatura:832/1.Biblioteca Digital Memoria de Madrid (disponible en

http://www.memoriademadrid.es/buscador.php?accion=VerFicha\&id=2242338num_id=98num_ total=11)

La prensa política femenina se convirtió también en un instrumento de organización y propaganda de las nuevas agrupaciones femeninas de la derecha católica, potenciando la difusión de un discurso movilizador de la ciudadanía femenina. Las revistas femeninas vinculadas al asociacionismo católico no eran una novedad y habian constituido una de las líneas de actuación preferente de la movilización de las mujeres católicas en las dos primeras décadas del siglo $\mathrm{XX}^{101}$, pero en 1932, en este contexto de preparación electoral, se crearán periódicos específicamente dirigidos al encuadramiento político de las mujeres en la derecha católica y monárquica. Se trata de un nuevo tipo de prensa femenina, diseñada para la preparación, organización y activismo político y, en muchos casos, vinculada orgánicamente a las agrupaciones femeninas de los partidos, como señalaba la revista Acción. Defensor de los intereses de la Mujer, ligada al partido de Acción Nacional de Gijón: "No, señores, este periódico no es de curas ni huele a sotana, ACCIÓN, ya lo dice su nombre es la bandera pequeñita de nuestro partido que empieza (...) Es un programa"102.

101 Muchas de las asociaciones femeninas católicas de acción social y obrera publicaron revistas específicamente dirigidas a las mujeres como La Mujer que vive de su Trabajo (Barcelona, 1906); Acción Femenina Católica (Barcelona, 1911); La Mujer Católica (Valencia, 1911); La Mujer y el Trabajo (Madrid, 1912); La Unión: revista de las Damas españolas (Madrid, 1916); La Unión Católica Femenina (Barcelona, 1921); Acción Católica femenina (Castellón, 1922), a las que se sumaban los boletines de Acción Católica de la Mujer en diversas ciudades, como Madrid o Córdoba.

102 Acción. Defensor de los intereses de la Mujer, 19-3-1932. 
Funciones primordiales de estas nuevas revistas eran el proselitismo y la preparación política de las mujeres ante el nuevo escenario electoral. Con ellas se ampliaba la difusión de la propaganda que se hacía llegar a aquellas mujeres que se mostraban más reticentes a una militancia activa en una agrupación política:

\begin{abstract}
"Esta preparación no nos la dará únicamente la adhesión a la Agrupación que merezca nuestra simpatía. Desde luego que esto es también necesario. Pero por la lectura adquiriremos aquella solidez de pensamiento, aquella garantía de nuestras convicciones, aquella decisión y audacia que nos permita intervenir en los frecuentes torneos de la conversación con la claridad y firmeza de pensamiento que da la posesión de la verdad.

Esa función del proselitismo por la Prensa es también esencialmente nuestra. No la debemos olvidar" ${ }^{103}$.
\end{abstract}

Con una vocación de ámbito nacional, pocos meses después de aprobarse la nueva Constitución, y claramente vinculadas a la concesión del voto femenino, aparecen las revistas Aspiraciones. Semanario de las derechas y Ellas. Semanario de las mujeres españolas ${ }^{104}$. La primera, vinculada a Acción Nacional ${ }^{105}$, comenzó a publicarse en enero de 1932 con la ayuda de El Debate ya que "Nada más necesario en estos instantes que un periódico de mujer. Nada más necesario porque somos una mayoría, porque tenemos el voto y porque, sobre todo, es justo que el pueblo conozca nuestra opinión, porque somos tan ciudadanas y tenemos tanto derecho a sentir como cualquier ciudadano..." 106.

En torno a esta revista se organizó una asociación con estructura similar a las asociaciones católicas (clases para asociadas, protección mutua, biblioteca con préstamo, residencia para señoritas) con unos estatutos fundacionales que recogian esa finalidad: “... la defensa de la mujer, sobre todo de la clase media, en sus derechos sociales y políticos, y que se instruya en sus obligaciones y que esté capacitada para ejercer su misión altísima de ir a las urnas a depositar su voto"107. El activismo comenzó de inmediato con llamamientos de unidad a todas las asociaciones católicas y políticas y ofreciendo la revista para que "se expresen con voz propia". De hecho, tanto Aspiraciones, como Ellas, dieron cobertura al

103 Ellas, no 10, 31-7-1932, p.12.

104 Se han realizado varios trabajos sobre estas dos revistas femeninas, como los de Danièle Bussy Genevois, "De la spécificité féminine de Ellas", en Typologie de la presse hispanique: actes du colloque, Université Rennes, 1984, pp. 133-139 y "Expresión y Represión: el caso de 'Aspiraciones' (1932-1935)", en Comunicación, cultura y politica durante la II República y la Guerra Civil: II Encuentro de Historia de la Prensa, Universidad del País Vasco, vol. 2: España (1931-1939), 1990, pp. 234-244. Sobre la revista Ellas, véase también Teresa M. Ortega López, "Hijas de Isabel. Discurso, representaciones y simbolizaciones de la mujer y de lo femenino en la extrema derecha española del período de entreguerras", Feminismo/s, nº 16, 2010, pp. 207-232 y Esther Collado Fernández, "Ellas, votantes contra la democracia. Modelos de participación política femenina desde la ultraderecha española en la Segunda República”, en La Historia, ¿Lost in translation? Actas del XIII Congreso de la Asociación de Historia Contemporánea, Universidad de Castilla-La Mancha, 2017, pp. 3231-3241.

105 Rebeca Arce ha destacado las conexiones en la dirección y alguna de las redactoras de la revista Aspiraciones con la revista Mujeres Españolas, que se publicó entre 1929 y 1930. Véase, Dios, Patria Hogar. La construcción social de la mujer española por el catolicismo y las derechas en el primer tercio del siglo XX, op. cit., p. 176.

106 Aspiraciones, no 1, 16-1-1932, p.4.

107 Ibid., Estatutos (Art. 2), p.13. 
asociacionismo femenino católico y a las secciones femeninas de los partidos de derecha.

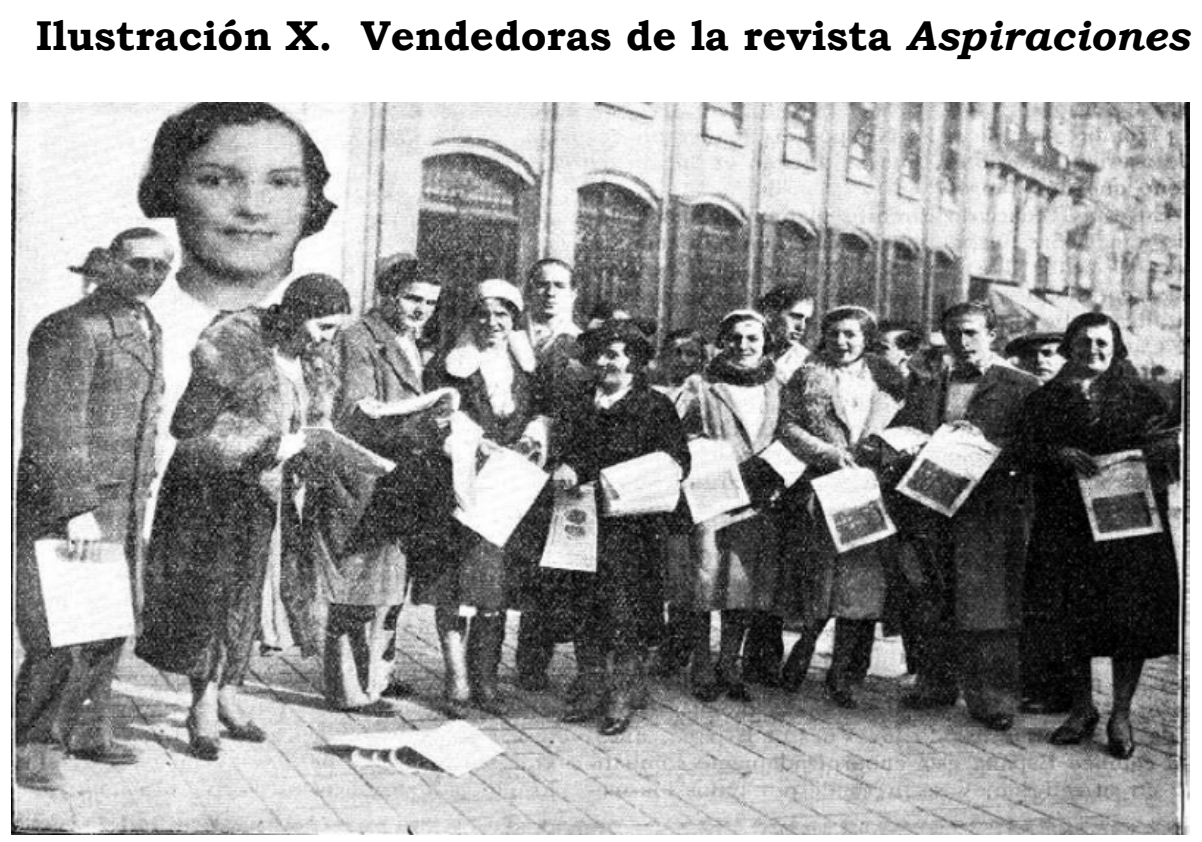

Pie de foto: "Nuestras valientes lindas y valientes vendedoras de la revista ASPIRACIONES acompañadas y defendidas por los bravos muchachos, que se entrenan para cuando llegue. Ya en alguna provincia lo venden también las señoras. ¡Ánimo! El triunfo es nuestro. Arriba, la señorita que vendió un número en 50 pesetas"

Fuente: Aspiraciones. Semanario de las derechas, n 6, 20 de febrero de 1932, p.1 (Biblioteca Nacional)

En una línea muy similar, empieza a publicarse en el mes de mayo de 1932 la revista Ellas, dirigida por José María Pemán. Se configuraba como una plataforma para la propaganda derechista y católica, como señalaba en su primer número: "Las puertas de nuestro periódico están abiertas a todas las mujeres españolas que coincidan en los principios fundamentales de nuestro programa...Ellas aspira a ser el periódico de todas las mujeres cristianas y patriotas"108.

En la prensa de esos años aparecen con frecuencia noticias de la publicación de revistas femeninas ligadas a las secciones femeninas locales de los partidos derechistas, como la revista Acción. Defensor de los intereses de la Mujer de Gijón, pero muchas de ellas tuvieron escasa duración o fueron clausuradas por problemas de censura o de financiación y, aunque conocemos su existencia, no se han conservado. En aquellas localidades donde no fue posible publicar una revista propia se utilizaron los diarios católicos que, como La Gaceta Regional de Salamanca, El Noticiero de Zaragoza o el Diario de Valencia, dieron amplia difusión a las noticias relacionadas con las secciones femeninas de los partidos 
derechistas, incluyendo en algún caso una sección específica ${ }^{109}$. Las revistas femeninas católicas ya existentes también ofrecieron información sobre ellas y algunas se remodelaron para adaptarse a la nueva coyuntura política, incorporando a sus secciones habituales otras de contenido político. Este sería el caso, por ejemplo, de Vida Católica Femenina que, heredera de una revista de larga vida como era La Unión Católica Femenina, fundada en 1921, sustituyó a esta en enero de 1933 para convertirse en portavoz de la nueva organización Cívica Femenina que, con una clara finalidad politico-electoral, integraba bajo la bandera de Acción Católica de la Mujer a las diversas entidades de esta orientación existentes previamente ${ }^{110}$.

Por otra parte, la prensa de ámbito nacional y orientación católica y conservadora (ABC, La Época, El Debate, El Siglo Futuro) también ayudó a la propaganda electoral dirigida a las nuevas votantes, aportando también información, consignas electorales y artículos sobre las secciones políticas femeninas de los partidos o de Acción Católica de la Mujer.

En las labores de propaganda y la captación de presuntas votantes las tareas de acción social fueron muy importantes y se vieron favorecidas por la existencia previa de redes asistenciales de las asociaciones femeninas católicas, en las que se integraban también muchas militantes de las secciones femeninas derechistas. En estas agrupaciones se organizaron secretariados o comités específicos para la asistencia social. La creación de roperos, la entrega de canastillas, las clases de instrucción y oficios, las mutualidades o las colonias veraniegas para las obreras fueron recursos muy utilizados para aumentar su ascendiente social y, por extensión, su influencia politica. Nos da idea de ello la insistencia con que los medios de prensa de estas asociaciones o la prensa afin hablaban del patronazgo que se debia ejercer sobre las afiliadas obreras de estas secciones, así como sobre las criadas y servicio doméstico femenino para captar su voto y convertirlas en agentes electorales en su propio ámbito familiar evitando que sus esposos, hijos o hermanos votasen las opciones republicanas de izquierda. En todas las agrupaciones esas tareas sociales se convirtieron en instrumentos políticos al dirigirse a la propaganda y la captación del voto femenino ${ }^{111}$. Así resumía una militante de la Asociación Femenina Tradicionalista las tareas que, además de los cursillos de divulgación política, las charlas explicativas o la organización del censo, realizaban para "atraer a la mujer al único camino apropiado a las necesidades de España": “...visitamos a los enfermos y a los pobres; tenemos diversas clases de enseñanza para las mujeres obreras...; en una palabra, nuestra actividad no decae ni un momento para lograr el triunfo en las elecciones próximas, a la vez que no olvidamos la cotidiana labor de nuestro Ropero de pobres..."112.

109 En el Diario de Valencia, además de una amplia y destacada cobertura a la actuación de Acción Cívica de la Mujer -con frecuencia en la portada del partido-, se incluyó una sección específica denominada "Voz Femenina".

110 Vida Católica Femenina, n 88, marzo 1933, p. 6.

111 Samuel Pierce, “The Political Mobilization of Catholic Women in Spain's Second Republic: The CEDA, 1931-6, op. cit., p. 76.

112 ABC, 15-11-1933. 
Las elecciones municipales parciales de abril de 1933 constituyeron el primer escenario de lucha electoral para las mujeres. Los buenos resultados obtenidos por las fuerzas de derecha reforzaron su percepción de que el voto femenino iba a ser importante. El propio Gil Robles señalaba que la intervención de las mujeres podia ayudar poderosamente a la evolución hacia las derechas, aunque se apresuraba a matizar que en estas elecciones no había sido un voto decisivo, "porque la mujer obrera ha seguido la orientación de los jefes de familia $\mathrm{y}$ porque en algunas aldeas se han negado a votar por considerarlo una innovación un poco extraña", lo que indicaba, a su juicio, "la necesidad de intensificar la educación ciudadana de la mujer en los pequeños centros de población"113.

Entre mayo y noviembre la actividad politica de las mujeres católicas y de las asociaciones femeninas de los partidos de la coalición de derechas se va a multiplicar, así como la propaganda y las consignas para votar en las elecciones. Era el deber que tenian que cumplir las mujeres de estas agrupaciones. Por "católicas y españolas", debían "levantarse el día 19 y salir perfectamente tranquilas a oír la primera misa. Y desde allí, después de elevar el corazón a Dios, ofrecerlo a la patria. Y sin titubeos (...) Dios demandará en su día la que pudiendo, no ha ido a votar por su Iglesia y por su Patria"114.

El día de las elecciones la afluencia de mujeres a las urnas fue masiva, por parte de todos los partidos, y también de las que militaban en las formaciones politicas derechistas. De la multitudinaria presencia femenina en colas, colegios electorales y en la calle fue testigo la prensa gráfica. Prácticamente, casi todos los periódicos católicos y derechistas, así como la mayoría de los de signo republicano, consideraron que el voto femenino habia decantado la victoria electoral hacia la derecha115. Las militantes derechistas, conscientes del papel que habian desempeñado en la campaña electoral, celebraron también el triunfo, pero en ciertos sectores se apreciaba un cierto regusto amargo, que traslucía una cierta crítica, no exenta de rechazo, hacia la marginación y subordinación de las afiliadas a los partidos de la derecha en la confección de las candidaturas, como denunciaba un artículo publicado en Ellas, con el significativo título de "Más mujeres en las Cortes":

\footnotetext{
"Sí; resulta poco airosa para las mujeres españolas cuya participación en la reciente contienda electoral ha sido encomiada de manera tan efusiva, la situación a que han quedado reducidas como resultado de esa norma que, sin estar aceptada y escrita en los programas politicos de la derecha, ha sido una realidad: las mujeres son electoras, pero no elegibles (...) En el acta de la señorita Bohigas han acabado para el feminismo derechista todos los avances y recompensas. Y lo más depresivo, lo que más nos entristece es que mientras nuestros partidos se han mostrado tan cortos y tacaños en corresponder a la abnegación, al sacrificio y a la generosidad de las mujeres, el partido socialista ha entregado tres de sus actas a otras tantas mujeres, después de reservarlas treinta puestos en sus candidaturas...
}

113 Ellas, no 51, 14-5-1933, pp. 8-9.

114 "La obligación de las lectoras de Aspiraciones", Aspiraciones, n 1 (2a época), 16-11-1933, p. 6

115 La prensa católica y derechista nacional y de provincias ilustró sus portadas con titulares como "Vivan las Mujeres españolas", "Honor a las Mujeres españolas", "Bendita seas Mujer", resaltando la encomiástica labor realizada por las mujeres de las agrupaciones derechistas. 
Mujeres generosas han colaborado meses y años en la obra de organización y de confección del censo; en preparar y adoctrinar a otras para la propaganda; mujeres entusiasmas han recorrido todas las provincias de España en campaña proselitista...

¿Qué recompensa han tenido todos estos trabajos y desvelos? ... en este terreno político en que ahora nos movemos la recompensa ha sido nula...

Exhortamos (...) a las mujeres para que procuren por todos los medios que se repare esta injusticia u olvido haciendo que de las vacantes ocasionadas por actas dobles se reserve alguna para otra mujer. Es preciso que en el Parlamento alcen la voz nuestras legitimas representantes para que se enfrenten con las que hasta ahora, falsamente, quisieron interpretar los sentimientos e ideales de las mujeres españolas.

A las Cortes deben ir más mujeres españolas, es decir, católicas”. ${ }^{116}$

\section{A MODO DE CONCLUSIÓN}

La nueva Constitución de 1931 concedió el derecho a voto a las mujeres y las formaciones derechistas lo utilizaron como un arma política en la contraofensiva católica contra la República. Ante el nuevo escenario políticoelectoral, impulsaron la organización de una estructura partidista o asociativa específica para las mujeres con el objeto de encuadrarlas políticamente bajo un discurso que, fundamentado en la defensa de la religión y de la patria, era común a todos los partidos del arco politico derechista.

Serian las propias mujeres católicas las encargadas de ir creando agrupaciones políticas a lo largo de los años 1932 y 1933 para canalizar la propaganda y la movilización femenina ante el reto electoral. La militancia previa en las asociaciones femeninas católicas y el bagaje adquirido en la práctica de la acción social por un amplio sector de estas mujeres explica en gran medida el rápido crecimiento y extensión por toda la geografia peninsular de estas secciones femeninas -especialmente notable en las adscritas a Acción Popular y a sus partidos satélites regionales -, que impulsaron una creciente e intensa politización que fue fundamental para el desarrollo de los partidos de la derecha católica, llegando a ser en algunos casos el núcleo originario de formación del partido en la localidad.

Aunque existirá diversidad en cuanto a la adscripción ideológica concreta, las secciones femeninas de los partidos del espacio político derechista mantendrán un estrecho contacto entre sí y utilizarán el mismo esquema organizativo, deudor del modelo de asociacionismo femenino católico desarrollado en las primeras dos décadas del siglo. Esta característica, además de la presencia de activas militantes católicas en los cuadros directivos de las nuevas agrupaciones políticas, demuestra la vinculación entre estas y el movimiento católico femenino, reforzada también por el hecho de que algunas de las agrupaciones políticas femeninas se constituirán bajo la tutela directa de Acción Católica de la Mujer, manteniendo un carácter apartidista.

Las agrupaciones femeninas contaron con un organigrama interno estructurado en varias secciones y secretarias, que debian atender a los frentes

116 Ellas, no 78, 10-12-1933, p.1. En una línea similar se pronuncia el Boletín de Acción Católica de la Mujer de Córdoba que, reproduciendo un artículo de El Defensor de Córdoba, titulado "Las mujeres y las elecciones" y firmado por Emigdio Molina, denunciaba la ausencia de mujeres en las candidaturas que se presentan a las elecciones, defendiendo que "Las derechas debieran llevar a las Cortes una docena de diputadas que en el futuro serian las que en torno suyo pondrian en pie a la casi totalidad de las mujeres españolas, pues la religión es el factor común que nos une a todas". Véase, no 150, noviembre de 1933, pp. 3-4. 
de actuación y trabajo previstos, como la formación política, la propaganda, la confección y depuración del censo electoral y la labor social-asistencial. Esta última se convirtió en un recurso muy utilizado para aumentar su ascendiente social y su influencia politica entre las mujeres de las clases populares y obreras. Participaron activamente en la propaganda de los partidos de la derecha católica, no solo en las tareas de oficina, como preparación de folletos, cartelería y sobres de papeletas, sino también como oradoras en conferencias y mítines, actuando en solitario o, en el caso de las más destacadas propagandistas, compartiendo tribuna con los grandes líderes nacionales o regionales de sus partidos. Impulsaron también la publicación de revistas dirigidas a las mujeres, diseñadas para difundir entre ellas un discurso movilizador de contenido eminentemente político.

Justificaron su actuación política como un deber de fe y patriotismo -incluso de carácter temporal-, pero algunas de ellas esgrimieron también una argumentación de tintes igualitarios, concibiéndola como un derecho que les correspondia plenamente por su condición de ciudadanas. Aunque estuvieron sujetas a la estructura de obediencia jerárquica de la dirección masculina de sus formaciones, que con frecuencia les llevó a actitudes de autocensura y subordinación a las decisiones que esta tomaba, gozaron de una cierta autonomía, que propició tras las elecciones algunas posturas críticas que, aunque minoritarias, reflejan un cierto rechazo a la marginación que habian sufrido en la elaboración de las candidaturas. Pero ello no puede negar la evidencia de que irrumpieron con fuerza en la escena pública, desempeñando un papel fundamental en la propaganda y en la confección del censo electoral, así como en la captación de afiliadas y votantes, y coadyuvando, sin duda, a la intensa movilización que cimentó el éxito electoral de la derecha católica en las elecciones de noviembre de 1933.

Fecha de envío / Submission date: 14/11/2017

Fecha de aceptación / Acceptance date: 23/12/2017 